\title{
Synergizing Ventures
}

\author{
Ufuk Akcigit, Emin Dinlersoz, \\ Jeremy Greenwood, and Veronika Penciakova
}

\section{Working Paper 2019-17 \\ September 2019}

\begin{abstract}
Venture capital (VC) and growth are examined both empirically and theoretically. Empirically, VC-backed startups have higher early growth rates and initial patent quality than non-VC-backed ones. VC backing increases a startup's likelihood of reaching the right tails of the firm size and innovation distributions. Furthermore, outcomes are better for startups matched with more experienced venture capitalists. An endogenous growth model, where venture capitalists provide both expertise and financing for business startups, is constructed to match these facts. The presence of venture capital, the degree of assortative matching between startups and financiers, and the taxation of VC-backed startups matter significantly for growth.
\end{abstract}

JEL classification: E13, E22, G24, L26, 016, 031, 040

Key words: venture capital, assortative matching, endogenous growth, IP0, management, mergers and acquisitions, research and development, startups, synergies, taxation, patents

https://doi.org/10.29338/wp2019-17

The Census Bureau's Disclosure Review Board (DRB) and Disclosure Avoidance Officers have reviewed this data product for unauthorized disclosure of confidential information and have approved the disclosure avoidance practices applied to this release (DRB approval numbers DRB-B0058-CED-20190605, DRB-B0116-CDAR-20180816, DRB-B0102-CDAR-20180711, CBDRB2018-CDAR-067, and CBDRB-2018-CDAR-063). The views expressed here are those of the authors and not necessarily those of the U.S. Census Bureau, the Federal Reserve Bank of Atlanta, the Federal Reserve System, or the Board of Governors and its staff. Any remaining errors are the authors' responsibility.

Please address questions regarding content to Ufuk Akcigit, Department of Economics, University of Chicago, 1126 E 59 th Street, Chicago, IL, 60637, uakcigit@uchicago.edu; Emin Dinlersoz, Center for Economic Studies, U.S. Census Bureau, 4600 Silver Hill Road, Suitland, MD 20746, emin.m.dinlersoz@census.gov; Jeremy Greenwood, University of Pennsylvania, Department of Economics, The Ronald 0. Perelman Center for Political Science and Economics, 133 South 36th Street, Suite 150, Philadelphia, PA 19104; or Veronika Penciakova, Research Department, Federal Reserve Bank of Atlanta, 1000 Peachtree Street NE, Atlanta, GA 30309-4470, veronika.penciakova@atl.frb.org.

Federal Reserve Bank of Atlanta working papers, including revised versions, are available on the Atlanta Fed's website at www.frbatlanta.org. Click "Publications" and then "Working Papers." To receive e-mail notifications about new papers, use frbatlanta.org/forms/subscribe. 


\section{Introduction}

Most firms are born small, stay small, and engage in little innovation throughout their lifetimes. ${ }^{1}$ Only a few become large, successful businesses that generate breakthrough innovations and contribute significantly to aggregate productivity growth. The fluctuations these large firms experience also matter for aggregate volatility. ${ }^{2}$ Venture capital (VC) is a potential catalyst that can take startups to the right tail of the firm-size and innovation distributions, and turn them into engines of growth. What role does VC play in the making of productive and innovative firms? To what extent do the synergies between entrepreneurs and venture capitalists matter for firm and aggregate outcomes? How critical is VC for the growth of the economy as a whole? Answers are provided empirically and through the lens of a macroeconomic model of innovation and growth where venture capitalists match with and nurture startups. The analysis suggests that the presence of venture capital in an economy, the degree of assortative matching between venture capitalists and startups, and the taxes applicable to VC-backed enterprises, matter significantly for growth.

Certain key events in the early stages of firms are the precursors of subsequent high growth. For instance, having a patent or a trademark early on is strongly predictive of the ultimate success of startups, as measured by rare events such as an IPO or a high-value acquisition - e.g., Fazio et al. (2016). Patenting and R\&D activity are positively correlated with measures of firm growth - e.g., Foster, Grim, and Zolas (2016). Furthermore, initial firm size is a good indicator of the ultimate success of a firm (Brown et al. (2017)). More generally, ex ante differences among startups appear to be important in understanding ex post firm outcomes at any firm age. Early characteristics of planned businesses predict well the ultimate formation of a business and its initial size (Bayard et al. (2018)), and its subsequent dynamics (Pugsley, Sedlacek, and Sterk (2017)). This paper contributes to the literature by establishing, both empirically and theoretically, that VC backing of startups in early stages is not only a key ingredient of eventual firm success, but also a significant contributor to aggregate innovation and productivity growth.

\footnotetext{
${ }^{1}$ The median startup in the U.S. barely grows over time (see, e.g., Decker at al. (2016) and Choi (2017)).

${ }^{2}$ Gabaix (2011) analyzes this "granular hypothesis" and finds that the shocks experienced by the top 100 firms in the "fat" right tail of the firm-size distribution account for a sizable fraction of year-to-year GDP fluctuations.
} 
To motivate the model and its analysis, the empirical analysis combines micro data on firms that receive VC funding, using the VentureXpert dataset, with data on all employer firms in the U.S., taken from the U.S. Census Bureau for the period 1980-2012. The lifecycle dynamics of VC-funded versus non-VC-funded firms are studied to understand the differences between them in terms of innovativeness, survival, and growth. Several key observations emerge. First, despite the fact that VC-backed startups are subject to higher initial selection, failure rates, and dispersion in growth outcomes, they are much more likely than non-VC-backed ones to eventually land in the right tail of the firm size and innovation distributions. In other words, VC appears to contribute disproportionately to the making of large and successful ("superstar") firms. The dominance of such firms in the U.S. economy has been increasing. ${ }^{3}$ Yet, the various mechanisms by which superstar firms emerge are not well understood. The findings here suggest that VC plays a critical role in taking startups to stardom.

Second, the synergies between venture capitalists and entrepreneurs matter for how far a VC-backed startup can go. The empirical analysis suggests strong evidence of assortative matching between entrepreneurs and financiers - the latter is composed of venture capitalists and others, such as banks. Startups that have more promising growth and innovation prospects tend to be funded by venture capitalists. Moreover, firms backed by venture capitalists with more experience and higher funding capabilities also tend to achieve significantly higher growth.

Third, VC involvement is critical for both firm-level and aggregate innovation. The data on firm-level patenting activity and patent quality reveals that VC disproportionately targets more innovative startups and spurs further innovation, with startups backed by more experienced venture capitalists engaging in better innovation. Innovation by VC-funded firms, especially the highly successful ones, imposes large productive externalities on the rest of the economy. This externality is evident in the disproportionately high level of citations to patents generated by successful VC-funded firms, which is one of the key contributions of such firms to growth.

\footnotetext{
${ }^{3}$ The consequences include the reallocation of labor to these firms, accompanied by a rising industry concentration of sales and a fall in labor's share of income-see, e.g., Autor et al. (2017).
} 
Motivated by the empirical findings, a macroeconomic model is developed to match salient features of VC in the U.S. data. In the model, venture capitalists nurture talented entrepreneurs by providing the necessary ingredients, advice and money, to bring a startup to the market. The framework stresses the complementarity between a talented entrepreneur's skill and a venture capitalist's. Not all talented entrepreneurs can find a venture capitalist to back their startup. As a result, they turn to more traditional sources of financing, such as banks. Banks provide a limited amount of expertise for a startup. For a talented entrepreneur, matching with a venture capitalist, as opposed to a bank, will result in a higher probability of success, a greater level of funding for startup research and development, and a higher productivity. Entrepreneurs starting more mundane enterprises are more likely to use bank financing. The opportunity cost for a venture capitalist is too high to mentor this type of startup. The model is calibrated using key micro-level moments from the empirical analysis. The calibrated model is used to assess how assortative matching between entrepreneurs and venture capitalists and the taxation of startups affect economic growth.

The empirical analysis adds to the large literature on the effects of VC funding on firm performance. In early work Kortum and Lerner (2000) studied the impact of VC funding on firm-level innovation between 1983-1992 and documented a significant impact. Puri and Zarutskie (2012) find that VC-backed firms exhibit higher growth and higher rates of IPO and M\&A activity, compared to otherwise similar firms. Some prior evidence suggests that VC monitoring of startups matters. For instance, Bernstein, Giroud, and Townsend (2015) show that venture capitalists' on-site involvement with the firms they fund generates both a higher level of innovation and a higher likelihood of success. ${ }^{4}$ More recently, Wong (2019) finds that a large portion of the variation in the duration of venture capital involvement across startups can be attributed to unobserved venture capitalist and match-specific effects. These findings point to potentially large treatment effects associated with venture capitalists' mentoring and monitoring of startups. The analysis here also offers further evidence of such effects.

The empirical work extends the prior literature in a number of dimensions. The selection of startups by venture capitalists based on the early innovation potential is explored, as

\footnotetext{
${ }^{4}$ Bernstein, Giroud, and Townsend (2015) exploit an exogenous reduction in VC oversight costs due to the opening of new airline routes that makes it easier for venture capitalists to visit their portfolio companies.
} 
well as the effects of $\mathrm{VC}$ treatment on innovation. In addition, a distinguishing aspect of the analysis is its focus on the effects of assortative matching between entrepreneurs and financiers. The presence and extent of synergies between venture capitalists and entrepreneurs is assessed. The analysis also quantifies the disproportionately large innovative externalities generated by VC-backed firms using citations to the patents applied for by these firms. Finally, the analysis here uses, in addition to the discrete measures of success for firms (such as IPO and M\&A), continuous measures of firm growth and innovation to define thresholds for success by the end of a typical VC contract. ${ }^{5}$

This paper contributes to the endogenous growth literature (e.g., Aghion and Howitt (1992), Klette and Kortum (2004), Lentz and Mortensen (2008), and Romer (1990)) by introducing VC financing into a model with endogenous technological progress. Ates (2014), Greenwood, Sanchez, and Wang (2019), and Opp (2019) are earlier attempts in a similar direction. Ates (2014) and Opp (2019) develop stylized Schumpeterian models of VC. In Ates' (2014) and Opp's (2019) analyses the research and development decisions by entrepreneurs are limited in the sense that they do not choose how far to launch their endeavor ahead of the pack. Also, the likelihood of success does not depend on the level of development funding. Greenwood, Han, and Sanchez (2018) model VC from a dynamic contract perspective. Their analysis focuses on the VC funding-round process. They don't explicitly model a banking sector as is done here. Ates (2014), Greenwood, Han, and Sanchez (2018), and Opp (2019) do not spotlight the initial selection process between different types of entrepreneurs and financiers, and the associated transition from ex ante promise to ex post success; that is, the unique set of facts assembled here. These papers also do not utilize data on firm growth and innovation in the early stages of privately-held startups to assess venture capital selection and treatment effects.

The current analysis also relates to two recent themes in the literature. First, it highlights the importance of financing for innovation and superstar firm creation. Therefore, it connects

\footnotetext{
${ }^{5}$ In particular, the likelihood of a venture capitalist taking a firm to the right tail of the firm-size and innovation distributions (90th percentile) within 10 years is assessed. The rationale for doing so is that even though a surviving VC-backed firm may not reach an IPO or M\&A stage, it can still achieve substantial growth and innovation on average, compared to non-VC-backed firms. Furthermore, among the firms that are involved in IPO or M\&A activity, the heterogeneity in performance can be more finely captured by continuous measures of firm growth. Measuring success in this fashion accounts for the contribution of all VC-backed firms to economic growth and aggregate productivity.
} 
with research by Autor et al. (2017), that documents the rise of superstar firms and their consequences for inequality. Bloom et al. (2017) and Gordon (2017) have argued that new ideas and innovations are getting harder and more expensive to generate. The current analysis highlights the importance of a good match between financiers and inventors, as well as the taxation of startups, for bringing new ideas to life. Second, a strand of literature stresses the importance of finance for economic development (e.g., Antunes, Cavalcanti, and Villamil (2008), Buera, Kaboski, and Shin (2011), Castro, Clementi, and MacDonald (2004), Cole, Sanchez, and Greenwood (2016), Erosa (2001), Gopinath et al. (2017), Levine (2005), Midrigan and Xu (2014), Moll (2014)). This work has typically focused on developing countries, and does not study whether different forms of finance (such as VC versus bank funding) matters for firm-level and aggregate innovation and growth.

\section{Some Stylized Facts on VC-Funded Firms}

To what extent does VC matter for turning startups into engines of growth and innovation in the economy? Empirical analysis is carried out to offer evidence on both the selection and treatment effects associated with venture capitalist involvement in a firm. This involvement may include, in addition to financial support, providing management advice and mentoring, industry expertise, and business network connections. These factors can lead to potentially different trajectories of growth and innovation for VC-funded firms.

The first goal of the empirical analysis is to explore the nature of selection by venture capitalists, based on key observable startup characteristics such as size, growth, and innovative activity. If venture capitalists tend to pick more promising projects to fund and nurture, there should be a disproportionate presence of VC among larger, faster growing faster, and more innovative startups.

The second goal is to understand the role that VC plays in catapulting firms to the right tail of the firm size and innovation distributions. How much does VC matter for a startup's survival, growth, and innovation? To investigate such effects, the outcomes of VC-funded firms are compared with those of a control group composed of non-VC-funded firms, which are chosen to match closely the funded firms on a number of key observable characteristics 
at the time of $\mathrm{VC}$ funding.

Finally, the empirical analysis also investigates the degree to which assortative matching and synergies prevail among venture capitalists and startups. Some venture capitalists may be better than others at identifying and nurturing promising startups. That is, the extent of selection and treatment by venture capitalists may depend on both the type of startup and the type of venture capitalist. Are startups with better growth and innovation prospects disproportionately targeted by more able venture capitalists? Do startups funded and supported by more capable venture capitalists achieve better outcomes? Answers are provided by studying the outcomes of startups backed by high- versus low-quality venture capitalists, where quality is measured using various characteristics of venture capitalists, such as expertise.

\subsection{Data}

To carry out the analysis, several datasets are brought together - see Appendix 11 for details on the construction of the dataset in the analysis, as well as supplemental information on all figures and tables. The main dataset that enables the tracking of firms over time is the U.S. Census Bureau's Longitudinal Business Database (LBD). The LBD contains longitudinally-linked information for each employer business in the U.S. starting in 1976, based on administrative data in the Census Bureau's Business Register (BR). Firms, and their constituent establishments, are observed in the LBD starting from the time of their first appearance as an employer business in administrative records. The LBD contains annual measures of employment, age, and payroll for both firms and establishments, and an annual revenue measure at the firm level for a large fraction of firms. ${ }^{6}$

Firms that receive VC funding are identified using the Thomson Reuters' VentureXpert database, which contains information on the dates of VC funding, the funding amount, and the identity of the venture capitalists. Firms in the VentureXpert dataset are first matched with the Census Bureau's Business Register (BR) using name and address matching techniques, and then linked to the LBD using unique firm and establishment identifiers. To include measures of innovation, the U.S. Census Bureau's patent-firm crosswalk is used to

\footnotetext{
${ }^{6}$ Data on revenue starts in 1997.
} 
identify firms with patenting activity. ${ }^{7}$ Citations for each patent are also incorporated from USPTO's PatentsView. In addition, Standard\&Poor's Compustat database is linked with the LBD to identify publicly-listed firms. The data set tracks all employer firms during the period 1980 to 2012 .

An important feature of the assembled dataset is that firms can be tracked over their entire life cycle, starting from their birth, as identified by the year of their first employment record, all the way to their death, which happens if the firm ceases to exist as an employer. Other key events in a firm's life cycle are also observed: the first injection of funds by a venture capitalist, the first patent application, and an IPO or an M\&A event. IPO events are identified using the Compustat database. M\&A activity is identified using a set of criteria based on how the ownership of the firm and its establishments changes from one year to another. ${ }^{8}$ The main firm outcomes in the analysis are survival, employment, and innovation as reflected by patenting activity and patent citations. ${ }^{9}$

\subsection{Which Firms do Venture Capitalists Select?}

Very few startups grow quickly and become successful firms, while most grow slowly or fail. Venture capitalists pick startups to fund and nurture very early during their formation. The age distribution of VC-backed startups at first VC funding is shown in Figure 1. Age is measured by the number of years since a startup first appears in the LBD as an employer business (birth). Negative age values correspond to cases where a startup receives funding even before it is first observed as an employer business. ${ }^{10}$ The striking feature of Figure 1 is the spike at age zero. About 42 percent of VC-funded firms receive their first funding in their

\footnotetext{
${ }^{7}$ The patent-firm crosswalk is a result of merging the USPTO's patent database with the LBD. We thank Nick Zolas for providing this crosswalk. See also Graham et al. (2015).

${ }^{8}$ For details on identifying IPOs and M\&As, see Section 11. We thank Joonkyu Choi and Javier Miranda for their assistance on identifying M\&A in the Census microdata based on their methodology.

${ }^{9}$ The results using revenue are briefly mentioned as an alternative to employment when appropriate. For firm size, employment is the preferred measure in the analysis, since annual revenue data is available starting only in 1997.

${ }^{10}$ Firms outside of the age range in Figure 1 are not included to prevent the disclosure of confidential information - they account for a small fraction of all firms that receive VC funding. In addition, the truncation of age at -5 guards against potential matching errors. Startups that receive VC funding 6 or more years before they hire their first employee are rare, and such cases may be more likely to indicate false positives in the name and addess matching procedures. Similarly, startups that receive VC funding after age +5 constitute a small fraction of all firms.
} 


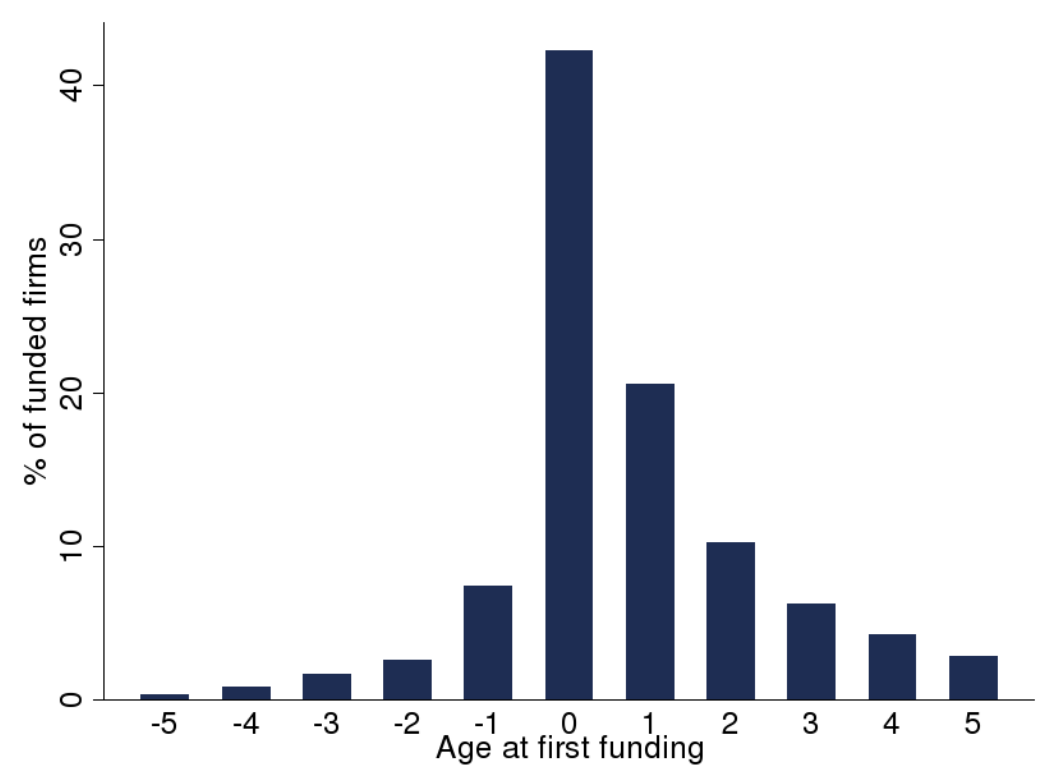

Figure 1: The distribution of firm age in the year of first VC funding. Age 0 corresponds to the first time that a startup is observed as a business with employee(s). Ages -5 to -1 correspond to startups for which the year of first VC funding occurs before the first observation of the startup as an employer.

first year as an employer business. There is also a considerable fraction of startups (about $15 \%$ ) that receive their first funding before they hire their first employee (age $<0$ ). ${ }^{11,12}$

Figure 2 plots the probability of ever-receiving VC funding by employment growth quintiles, where the quintiles are based on growth during a startup's first three years as an employer business. ${ }^{13}$ The probability of funding jumps nearly two hundred-fold as one moves from the lowest quintile to the highest. This sharp rise suggests that venture capitalists tend to select firms that exhibit relatively high growth in their early phases. ${ }^{14}$

The relationship between a startup's probability of receiving its first VC funding within five years of its first patent application and the quality of its early patents is plotted in Figure 3. The quality of early patenting is measured by the total number of citations for all

\footnotetext{
${ }^{11}$ Most likely, these firms receive VC funding at a stage when they are still non-employers; i.e., businesses with no payroll/employees. Recent work by Bento and Restuccia (2019) highlights the contribution of non-employer businesses to business dynamism in the United States.

${ }^{12}$ For the rest of the analysis, startups that receive VC funding before age zero are treated as having received funding at age zero. This approach is necessary because several key variables (e.g., employment and patenting) for the subsequent analysis are available only for employer firms starting at age zero.

${ }^{13}$ The employment growth rate for the first three years of a firm's life-cycle is measured as $g=2 \times$ $\left(e m p_{t+2}-e m p_{t}\right) /\left(e m p_{t+2}+e m p_{t}\right)$, where $t$ is the year a startup is first observed as an employer business.

${ }^{14} \mathrm{~A}$ similar conclusion emerges when growth is measured in terms of revenue instead of employment.
} 


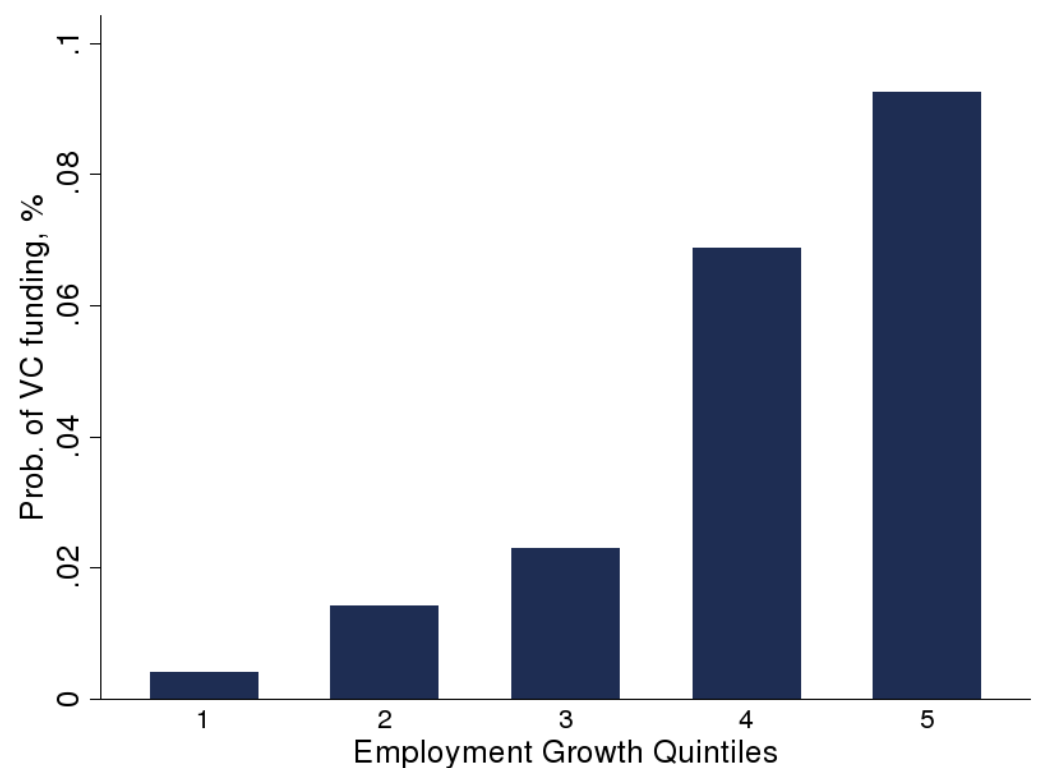

Figure 2: Firm employment growth and the probability of VC funding at any point in the firm life-cycle. Employment growth is the 3-year growth rate for a startup, starting from the first year of observation as an employer.

patents within (up to) three years after the first patent (and before any VC funding). Figure 3 suggests that VC funding is concentrated in startups with relatively high early innovation. The probability of receiving VC funding for startups in the bottom quintile of the patent quality distribution is only about 1 percent, but rises to nearly 6 percent in the top quintile. Note that the probability of VC-funding is overall much higher for the case of startups that have a patent (Figure 3), compared with all startups considered in Figure 2. The former sample (startups with early patent activity) is much smaller and represent a highly selective group of innovating firms, resulting in much higher rates of $\mathrm{VC}$ funding overall.

Table 1 presents some statistics on startups in their year of first VC funding. The average employment at funding is normalized to one for VC-funded startups that are in the top decile ( $\geq 90$ th percentile) of the firm employment distribution in the first funding year. For nonVC-funded startups, the hypothetical age at first funding is set to the average age at which a VC-funded firm receives funding. ${ }^{15}$ From the numbers in Table 1 it can be calculated that at the time of funding the average employment of $\mathrm{VC}$-funded firms is about 3 times larger

\footnotetext{
${ }^{15}$ The average age at VC funding is calculated using the age distribution of VC-funded firms in the year of first VC funding, assuming a VC-funding age of zero for firms that receive VC funding before age zero.
} 


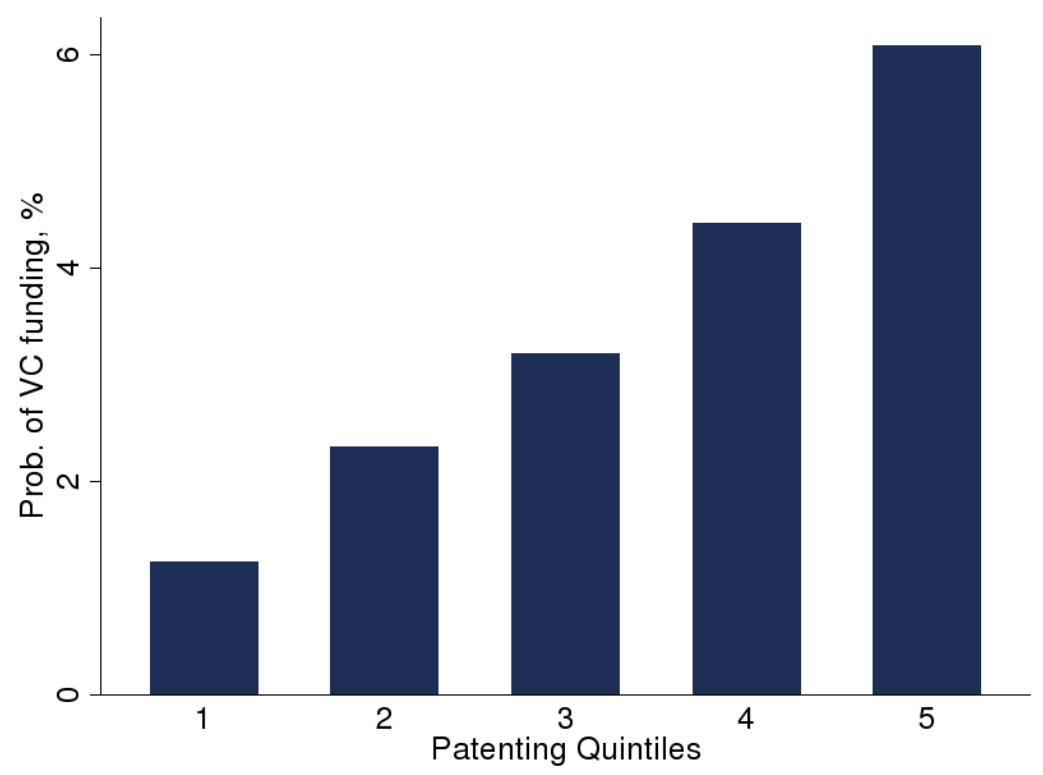

Figure 3: The quality of a firm's early patenting quality and the probability of VC funding. The figure is conditional on having a patent. Patenting quintiles pertain to the quality distribution for startups' early patenting activity, measured within (up to) three years of a startup's first patent and before any VC funding. Patent quality is the number of citations received, demeaned by average citations in patent class, excluding self-citations. The probability of $\mathrm{VC}$ funding is measured within 5 years of the first year of patenting.

than that of non-VC-funded firms. ${ }^{16}$ VC-funded startups in the top decile of the employment distribution are about 43 percent larger than the non-funded firms that are also in the top decile. There is not a big difference, however, in the average employment of funded versus non-VC-funded firms in the bottom 90 percent $\left(\leq 90\right.$ th percentile). ${ }^{17}$

There is strong evidence that the initial match between a financier and a startup is highly assortative in nature: better startups tend to match with venture capitalists disproportionately. One way to see this is to look at the fraction of VC-funded firms that are in the

\footnotetext{
${ }^{16}$ The ratio of the average sizes is given by $r=\left(E_{V C} / N_{V C}\right) /\left(E_{N o n-V C} / N_{N o n-V C}\right)$, which can be written as

$$
\frac{\left(E_{V C} / E\right) /\left(N_{V C} / N\right)}{\left(E_{N o n-V C} / E\right) /\left(N_{N o n-V C} / N\right)}
$$

where $E$ is the total employment and $N$ is the total number of firms. From Table 1, $E_{V C} / E=0.25 \%+$ $0.04 \%=0.3 \%, N_{V C} / N=0.03 \%+0.07 \%=0.1 \%, E_{N o n-V C} / E=57.8 \%+41.9 \%=99.7 \%$, and $N_{N o n-V C} / N=$ $10.7 \%+89.2 \%=99.9 \%$. Therefore, the ratio $r$ is given by $(0.3 / 0.1) /(99.7 / 99.9)=3.0$.

${ }^{17} \mathrm{~A}$ caveat to these comparisons of startup sizes at the time of $\mathrm{VC}$ funding is that most startups at this stage are very small, and there is not a very large variation in size across firms within the top 10 percent or within the bottom 90 percent. Firm sizes diverge as startups grow and selection takes place, as discussed below.
} 
top decile, and compare it with the corresponding fraction for the non-VC-funded ones. As shown in Table 1 , these fractions are $p_{V C}=0.326$ and $p_{N o n-V C}=0.107$, respectively. The observed odds ratio is therefore $(0.326 / 0.674) /(0.107 / 0.894) \simeq 4$. Random matching would imply $p_{V C}=p_{N o n-V C}=0.10$, or an odds ratio of 1 . To assess formally the difference between the groups, a two-sample test of proportions (the null $H_{0}: p_{V C}-p_{N o n-V C}=0$ versus the alternative $\left.H_{A}: p_{V C}-p_{N o n-V C}>0\right)$ is implemented where standard errors are adjusted for clustering within each venture capitalist. This adjustment is necessary, because in many cases a venture capitalist matches with many firms, and among these matches the assumption of independence (the standard assumption in a test of the equality of proportions) is unlikely to hold. The two-sample test rejects the null hypothesis in favor of the alternative at a significance level much higher than 1\%, suggesting the presence of strong assortative matching between startups and financiers. ${ }^{18}$

Overall, the patterns in Figures 2, 3, and Table 1 suggest the presence of a high degree of selection in VC funding. Among startups in the economy, venture capitalists choose those that are on average larger, and exhibit higher early-stage employment growth and innovation. Furthermore, venture capitalists select these startups very early in their lifecycles, as indicated by the firm age distribution at the time of first VC funding (Figure 1). This timing is consistent with venture capitalists' reliance on their experience and expertise in assessing the promise of a startup almost immediately upon its inception. ${ }^{19}$

\subsection{How Much do Venture Capitalists Matter?}

Next, consider the effects of venture capitalist involvement on the post-funding evolution of a startup. ${ }^{20}$ To assess the magnitude of these effects, the selection of startups by venture

\footnotetext{
${ }^{18}$ In addition, both of the individual hypotheses, $p_{V C}=0.10$ and $p_{N o n-V C}=0.10$, are rejected in favor of the alternatives $p_{V C}>0.10$ and $p_{N o n-V C}>0.10$.

${ }^{19}$ Anecdotal evidence suggests that venture capitalists may even target early stage projects with no business plan at all. See, for example, the interview "Venture capitalism: Investing today in the companies of tomorrow" by Ryssdall and Hollenhorst in NPR's Marketplace, which features venture capitalist Ann Miuro-Ko's investment of $\$ 1 \mathrm{M}$ in an early project that consists of merely a few math papers written by a Stanford professor. (https://www.marketplace.org/2018/08/28/tech/corner-office/venture-capitalisminvesting-today-ideas-tomorrow)

${ }^{20}$ One caveat is that no direct measures of $\mathrm{VC}$ involvement are available, such as the presence of a venture capitalist on the management board of a funded firm or the amount of time spent by a venture capitalist on
} 
Statistics FOR Firms-YeAR of First VC Funding

\begin{tabular}{lllllllll}
\hline \hline & \multicolumn{9}{c}{ Share of (\%) } & \multicolumn{2}{c}{ Average } \\
\cline { 2 - 7 } & \multicolumn{2}{c}{ Firms } & \multicolumn{2}{c}{ Empl } & Firms by funding type & Empl (Rel) \\
\hline Type & $\geq 90$ th & $\leq 90$ th & $\geq 90$ th & $\leq 90$ th & $\geq 90$ th & $\leq 90$ th & $\geq 90$ th & $\leq 90$ th \\
\hline VC funded & 0.03 & 0.07 & 0.25 & 0.04 & 32.6 & 67.4 & 1.00 & 0.05 \\
Non-VC funded & 10.7 & 89.2 & 57.8 & 41.9 & 10.7 & 89.4 & 0.70 & 0.06 \\
\hline
\end{tabular}

Table 1: A firm's type refers to whether or not it is in the top decile (90th percentile) for employment at the time of first VC funding. Average employment is measured with respect to the VC-funded firms in the top decile. Non-VC-funded firms are assigned a hypothetical age of funding equal to the average age at first funding for VC-funded firms. All figures are rounded for disclosure purposes.

capitalists must be taken into account. To control for selection based on observables, a group of non-VC-funded firms that closely match VC-funded firms on a number of key characteristics are identified. A coarsened exact matching is implemented to form a control group for VC-funded firms. Because there is a large number of potential matches in the constructed dataset, it is possible to find exact matches for any VC-funded firm based on many of the key characteristics. Each firm that received first VC funding in a given year is matched with non-VC-funded firms in the same year that is of the same age, in the same narrowly defined employment bin, operates in the same 4-digit NAICS industry, has the same multi-unit/single-unit firm designation, and is located in the same state. ${ }^{21}$ The treated and control groups are then used to perform an event study that considers employment and the quality-adjusted patent stock as the key outcome variables — see Appendix 11.3.4 for further details on the construction of event study samples.

Figure 4 plots the evolution of (ln) average employment for VC-funded firms and their matched counterparts. The data points in Figure 4 are relative to the $(\ln )$ average employment of VC-funded firms at the time of first VC funding $(t=0)$, which is normalized to 1. The two types of firms are followed up to 10 years after they receive VC funding, and up to 3 years before that point - that is, only the firms that receive $\mathrm{VC}$ at ages 1, 2 or 3 are included. ${ }^{22}$ The horizon of 10 years is chosen to approximate the duration of VC contracts, mentoring an entrepreneur.

${ }^{21}$ The main firm size measure, employment, cannot always be matched exactly conditional on other match criteria, especially for relatively large VC-funded firms. Instead, a coarser matching based on employment bins is considered.

${ }^{22}$ After first funding, firms are followed until the point where they fail, get involved in an M\&A or IPO, 


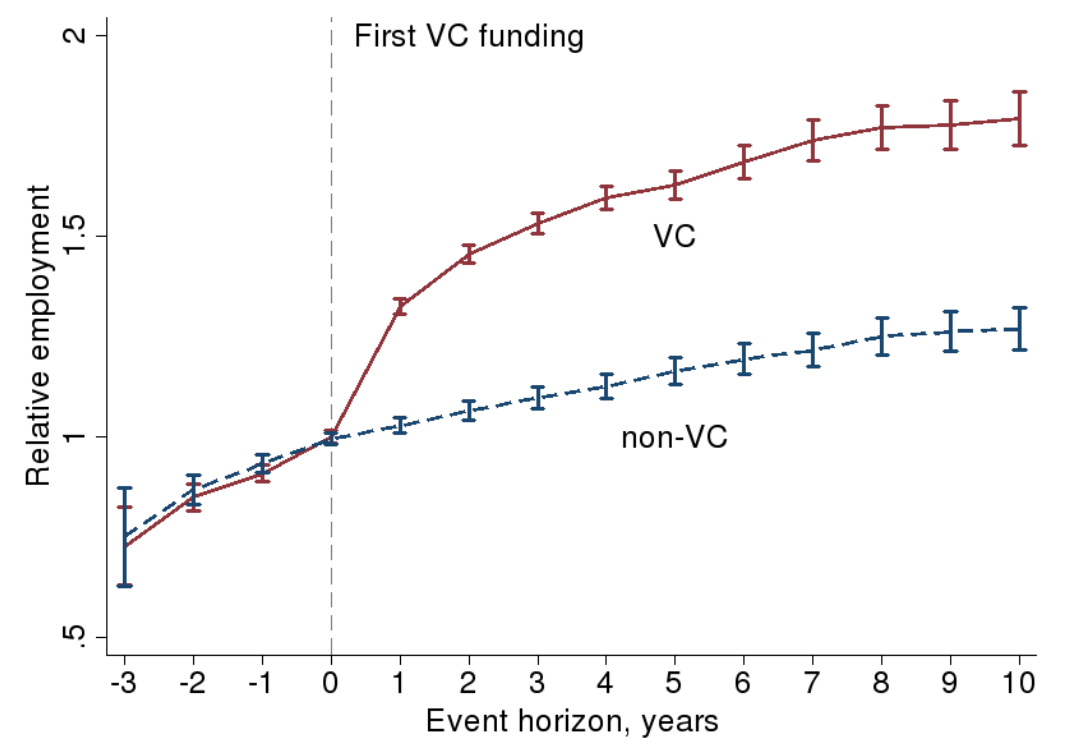

Figure 4: The evolution of average employment before and after first VC funding date: VC-funded firms versus non-VC-funded controls. The observations are relative to average employment (normalized to 1) for VC-funded startups in the year of first VC funding, $t=0$.

which is about a decade.

The two groups exhibit virtually identical trajectory of average employment before VC funding, indicating that the matching algorithm does a decent job of accounting for the pre-VC-funding trends. The funded firms, however, grow, on average, much more following first funding. Average employment increases by approximately 475 percent by the end of the horizon for VC-funded firms, whereas growth is much more modest for the matched non-VC-funded control group (about 230 percent). Based on these differential growth rates, the treatment by venture capitalists accounts for up to nearly half of the growth experienced by VC-funded startups. ${ }^{23}$

The failure rate of VC-funded firms in the 10 years following funding is slightly larger than that of the non-funded firms (36 percent versus 34 percent). The growth rates of VCfunded firms, conditional on survival, exhibit considerable dispersion. These rates are also

or the 10th year after VC-whichever occurs the earliest. That is, the samples are not balanced panels; the evolution of average employment is influenced by selection due to firm failure, M\&A, or IPO. In addition, firms that receive VC funding at age zero are excluded, since these firms have no observations for the pre-VC period for a proper event study. Last, all firms that report zero employment are excluded from the analysis for both groups.

${ }^{23}$ Although not reported, the patterns are similar if revenue is considered as a measure of firm size. Note that revenue is not used as a variable in selecting the control group. 


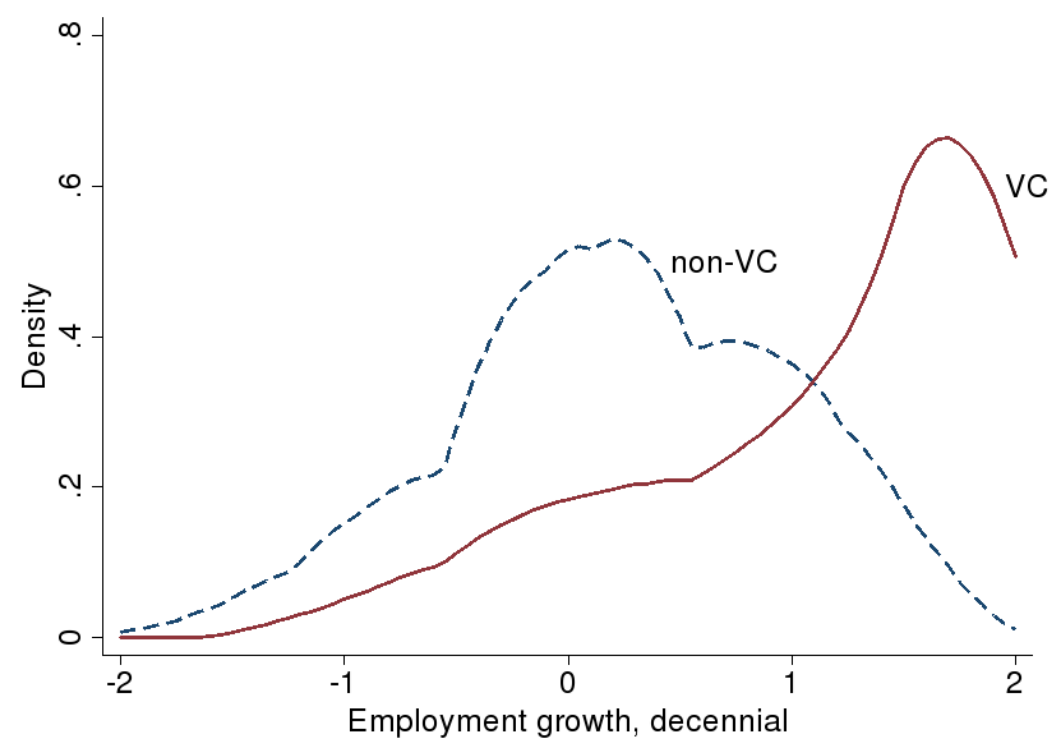

Figure 5: The distribution of the employment growth rate, measured 10 years after first VC-funding, for both VC-funded and all non-VC-funded firms (not just the ones that are matched with VC-funded firms). The figure is conditional on survival.

very different from those of non-VC-funded startups. The kernel density estimates for the growth rates of employment conditional on survival 10 years after VC funding are plotted in Figure 5 for VC-funded and all non-VC-funded firms. ${ }^{24}$ The growth-rate distribution for VC-funded firms is negatively skewed, with a large mass of firms beyond the growth rate of 100 percent, and a peak density around the growth rate of 200 percent. In contrast, non-VC-funded firms have a much more symmetric growth-rate distribution that is centered slightly above zero. ${ }^{25}$ The dispersion of growth rates is also higher for VC-funded firms. VC involvement is associated with more dispersed, but on average much higher, employment growth rates conditional on survival. ${ }^{26}$

The evolution of innovative activity, as measured by the (ln) quality-adjusted patent stock, is shown in Figure $6{ }^{27}$ The treatment and control groups underlying this figure are

\footnotetext{
${ }^{24}$ This is done in a manner similar to footnote 13.

${ }^{25}$ The relatively low median 10-year growth rate for non-VC-funded firms is consistent with earlier findings that indicate a very low average growth rate for startups in the U.S. economy - see, for example, Decker et al. (2016) and Choi (2018).

${ }^{26}$ The growth patterns are similar if revenue is used instead of employment as the outcome measure.

${ }^{27}$ This figure only includes firms that receive VC funding at ages 1 and 2 only, compared to Figure 4, which also includes firms that receive funding at age 3 . The reason is that the control group for firms that receive $\mathrm{VC}$ funding at age 3 is much smaller and only contain a small number of firms that have patents, leading to a very large confidence interval for the average patent stock.
} 


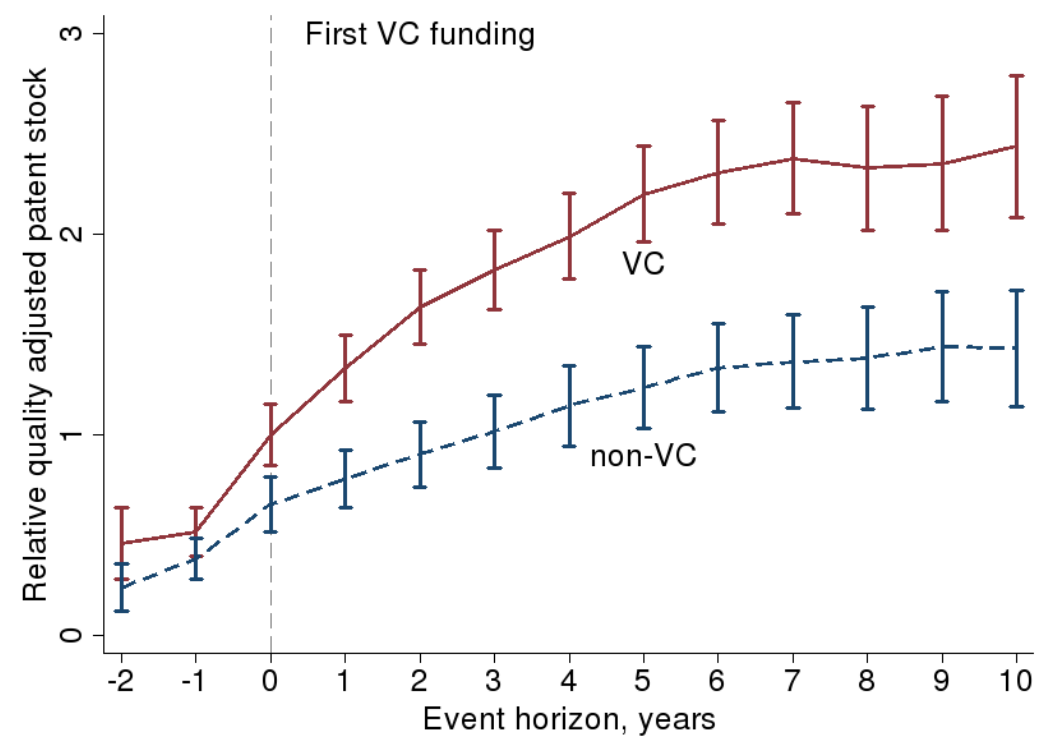

Figure 6: The evolution of the average quality-adjusted patent stock before and after first VC funding date: VC-funded firms versus non-VC-funded controls. The observations are relative to the average patent stock (normalized to 1) for VC-funded firms in the year of VC funding, $t=0$.

restricted to firms with patents, but the two groups are not matched based on patent quality similarity - as matching based on this criterion turns out to yield no close matches for many treated firms. As in Figure 4, the observations are relative to the (ln) average patent stock of VC-funded firms at the time of funding $(t=0)$, which is normalized to 1 . Pre-VC trends for the two groups do not differ substantially, again indicating a close match based on the same criteria used in the employment case even though patent stock similarity is not one of the criteria. The post-VC trends indicate that VC-funded firms experience, on average, a much higher growth in their patent stock. The VC-funded firms' average patent stocks grows by about 1, 100 percent, as opposed to about 440 percent for the control group. These rates suggest that up to 60 percent of the growth in the patent stock can be attributed to treatment by venture capitalists.

The results indicate strong post-funding effects associated with VC involvement. VCbacked firms achieve on average better outcomes in terms of employment and innovation, after controlling for selection based on observables. Consequently, VC-backed startups are much more likely to make it into the right tail of the firm employment and innovation 
distributions, compared with non-VC-funded ones. ${ }^{28}$ Overall, venture capitalists appear to play an important role in fostering successful firms and increasing skewness in firm outcome distributions.

\subsection{Heterogeneity in Venture Capitalist Involvement}

Are the effects of venture capitalist involvement larger for more experienced venture capitalists? To answer this question, venture capitalists in the sample are first divided into two groups: low versus high quality. A venture capitalist is labelled "high quality" if the number of deals it is involved in over the entire sample period is in the 90th percentile of the distribution over the total number of deals by venture capitalists, and "low-quality" otherwise. ${ }^{29}$ This quality measure is meant to capture the experience or expertise of a venture capitalist. Alternative definitions of quality are also considered, as discussed below. Then, VC-funded firms are divided into two mutually exclusive groups: those funded by high-quality venture capitalists and those funded by low-quality ones. A startup is the in the high quality group if $50 \%$ or more of the venture capitalists that fund the startup in its first year of funding are considered high quality. This rule is adopted because some startups are funded by multiple venture capitalists, but the data does not provide details on the lead venture capitalist, or the one with the highest funding contribution. ${ }^{30}$

Figure 7 plots the evolution of (ln) average employment of firms by venture capitalist quality. Observations are relative to the (ln) average employment level of startups funded by high-quality venture capitalists measured at the time of first funding $(t=0)$, which is normalized to 1 . In the pre-funding periods $(t<0)$, the trajectories for the two groups are similar, but at $t=0$ the average employment is higher for startups funded by high-quality venture capitalists. In the years following VC funding $(t>0)$, firms funded by high-quality

\footnotetext{
${ }^{28}$ Some additional statistics on the superior performance of VC-backed, relative to non-VC-backed, firms are presented in Section 6.

${ }^{29} \mathrm{It}$ is common for VC-funded firms to receive funding from multiple venture capitalists. Based on the venture capitalist quality/experience measure constructed, if 50 percent or more of a firm's funders are of high quality, the firm is considered to be funded by high-quality venture capitalists. If instead, more than 50 percent of its funders are of low quality, it is considered to be a firm funded by low-quality venture capitalists.

${ }^{30}$ In the following analysis, the sample of VC-funded firms is larger than the one used to generate Figures 4 and 6 , because the latter consider only the VC-funded firms for which close matches within the set of non-funded firms are available. In addition, some VC-funded firms have missing funding information, which generates additional differences from the samples used in Figures 4 and 6.
} 


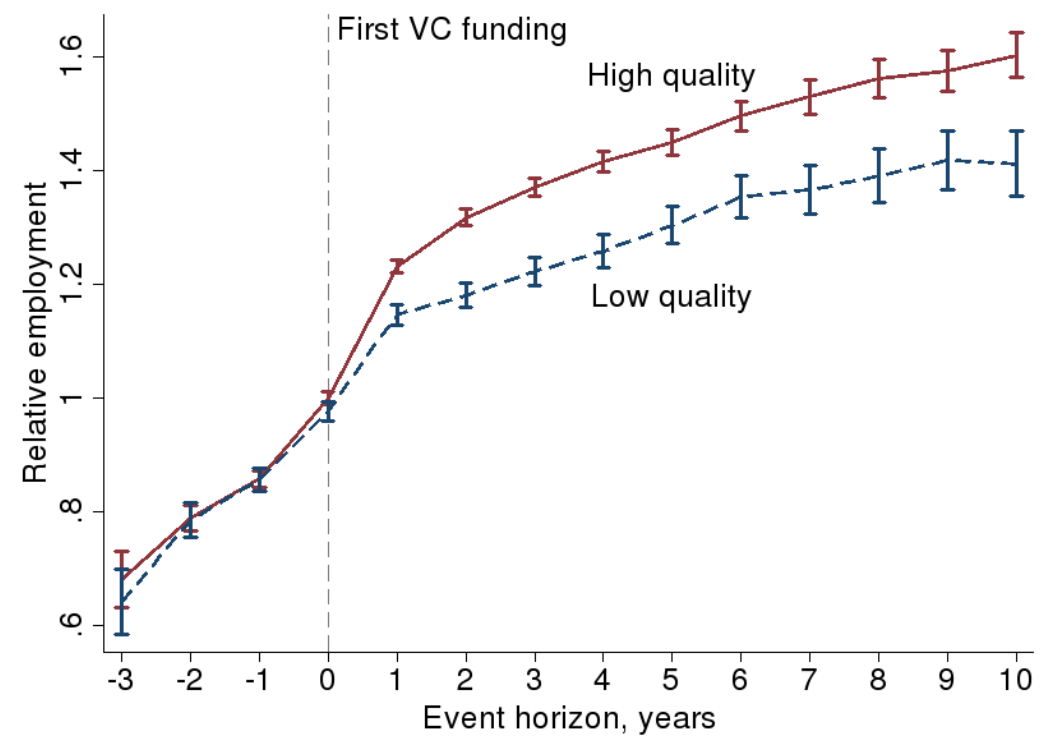

Figure 7: The evolution of average employment before and after first $\mathrm{VC}$ funding, by the quality of the venture capitalist. The observations are relative to the average employment (normalized to 1) for startups funded by high-quality venture capitalists in the year of first VC funding, $t=0$.

venture capitalists also grow significantly more on average. Following a notable jump at $t=1$, the gap between the trajectories continues to open up. By the end of the horizon, average employment grows by about 400 percent in the high-quality group, and by about 320 percent in the low-quality group.

A similar picture emerges when the event study is repeated for the (ln) average qualityadjusted patent stock, as shown in Figure $8 .{ }^{31}$ While the difference between the firms funded by high-quality versus low-quality venture capitalists is small for the periods before funding $(t<0)$, a gap appears at $t=0$, which grows over time after funding. By the end of the horizon, the average patent stock grows by nearly 50-fold for the high-quality group, and by only about 19 -fold for the low-quality group. ${ }^{32}$

There is also some evidence that the quality (experience) of a venture capitalist matters

\footnotetext{
${ }^{31}$ Note that the pre-VC period extends to 3 periods in this figure, compared to only 2 periods in the analysis associated with Figure 6 . The reason is that in the latter analysis the control group is very small and does not include a large enough number of patenting firms for $t<-2$.

${ }^{32}$ The findings in Figures 7 and 8 are qualitatively similar when revenue is considered as an alternative outcome. Many of the results are also similar when alternative measures of quality for venture capitalists are considered - for instance, when quality is measured by total all-time funding by a venture capitalist, by average funding per year, or by the average number of deals per year.
} 


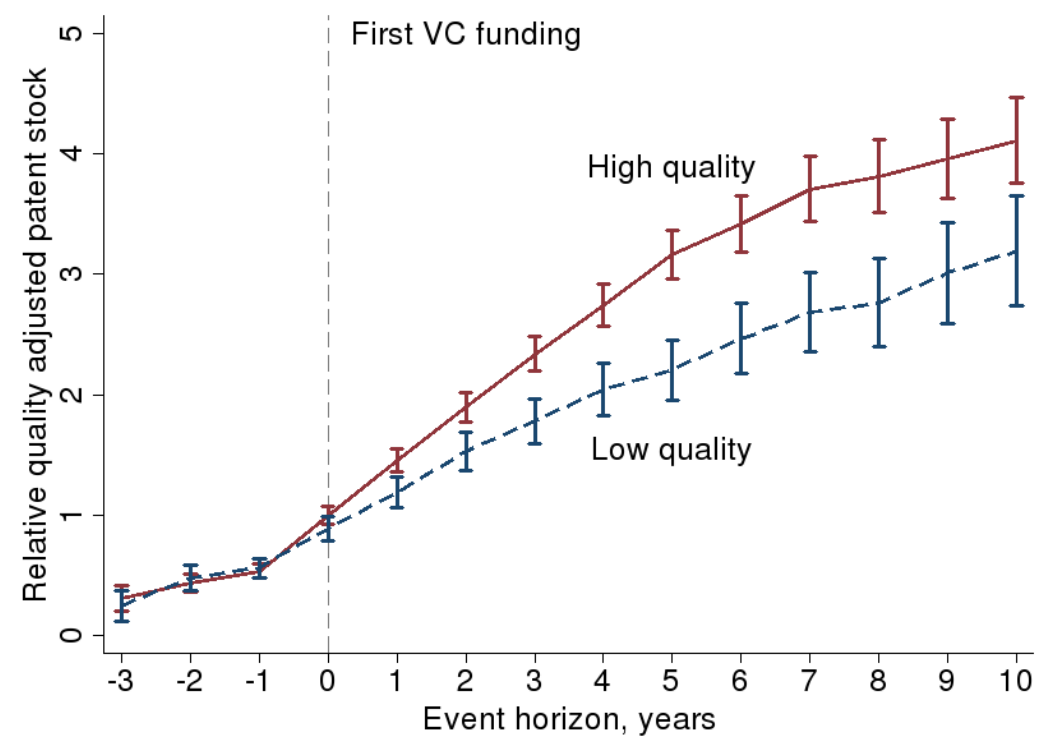

Figure 8: The evolution of the average patent stock before and after first VC funding, by the quality of the venture capitalist. The observations are relative to the average patent stock (normalized to 1) for startups funded by high-quality venture capitalists in the year of first VC funding, $t=0$.

beyond just the amount of initial funding provided. To assess such effects that are not directly observed, the employment of a startup in the year of failure, an M\&A event, or at 10 years after funding (whichever occurs first) is projected on the initial amount of VC funding and a dummy variable that indicates backing by a high-quality venture capitalist - this variable controls for venture capitalist-specific fixed factors in a reduced form. Employment and age at the time of funding are also included to control for the initial characteristics/conditions of startups that may reflect selection as well as entrepreneurial ability. Because some startups fail or get involved in M\&A before the end of the 10-year horizon, the number of years from first funding is also added to proxy for the duration of venture capitalist involvement - this variable takes on a value of at most 10 depending on the timing of failure or M\&A activity. Finally, industry and year fixed effects (associated with the year of failure or M\&A, or with the 10th year after first funding) are included to control for variation across sectors, and economy-wide factors at the time of measurement that can influence firm outcomes.

Results from alternative specifications are shown in Table 2. In all specifications, the initial funding level has positive and highly significant coefficients, which imply that a 1 
Employment Outcomes and Quality of Venture Capitalists

\begin{tabular}{|c|c|c|c|c|}
\hline \multirow[b]{2}{*}{ Independent Variables } & \multicolumn{4}{|c|}{ Employment at 10 years from funding (ln) } \\
\hline & 1 & 2 & 3 & 4 \\
\hline High-quality funder (dummy) & $\begin{array}{c}0.253^{* * *} \\
(0.030)\end{array}$ & $\begin{array}{c}0.260^{* * *} \\
(0.029)\end{array}$ & $\begin{array}{c}0.292^{* * *} \\
(0.028)\end{array}$ & $\begin{array}{c}0.274^{* * *} \\
(0.028)\end{array}$ \\
\hline Equity at first funding (ln) & $\begin{array}{c}0.414^{* * *} \\
(0.013)\end{array}$ & $\begin{array}{c}0.368^{* * *} \\
(0.012)\end{array}$ & $\begin{array}{c}0.352^{* * *} \\
(0.012)\end{array}$ & $\begin{array}{c}0.347^{* * *} \\
(0.012)\end{array}$ \\
\hline Employment at first funding (ln) & & $\begin{array}{c}0.267^{* * *} \\
(0.008)\end{array}$ & $\begin{array}{c}0.278^{* * *} \\
(0.008)\end{array}$ & $\begin{array}{c}0.249^{* * *} \\
(0.008)\end{array}$ \\
\hline Age at first funding & & & $\begin{array}{c}0.074^{* * *} \\
(0.006)\end{array}$ & $\begin{array}{c}0.082^{* * *} \\
(0.006)\end{array}$ \\
\hline Years since first funding & & & & $\begin{array}{c}0.146^{* * *} \\
(0.004)\end{array}$ \\
\hline Industry F.E. & Yes & Yes & Yes & Yes \\
\hline Year F.E. & Yes & Yes & Yes & Yes \\
\hline$N$ & 14,000 & 14,000 & 14,000 & 14,000 \\
\hline$R^{2}$ & 0.17 & 0.23 & 0.24 & 0.30 \\
\hline
\end{tabular}

Table 2: Standard errors clustered by industry are in parentheses. The high-quality funder dummy equals 1 , if $50 \mathrm{in}$ the top decile of the distribution of the total number of deals made by venture capitalists. The omitted category is the low-quality funder. The regressions include a constant, and industry and year fixed effects. All figures are rounded for disclosure purposes.

percent increase in initial funding is associated with about a 0.35 to 0.41 percent increase in ultimate employment. Startups that are larger at the time of funding also tend to be even larger at the end of the observation period. The key coefficient estimates, associated with the dummy for high-quality venture capitalists, all indicate a positive association between high quality and ultimate employment. In particular, controlling for the funding level and other observables (specification 4), startups backed by a high-quality venture capitalist are estimated to end up with approximately 32 percent larger employment. ${ }^{33}$ This finding suggests that firms matched with higher quality (experience) venture capitalists have better outcomes, even conditional on the amount of initial funding. ${ }^{34}$

Overall, the empirical findings suggest both strong selection and treatment effects as-

\footnotetext{
${ }^{33}$ The estimated effect is given by $e^{0.274}-1 \simeq 0.32$.

${ }^{34}$ The conclusions from Table 2 also apply to alternative measures of quality for a venture capitalist. For various quality measures used, there is a positive association between the ultimate employment of a startup and the quality of the venture capitalist associated with that startup.
} 
sociated with venture capitalist involvement. VC funding is concentrated in firms that are younger, larger, and that have better growth and innovation prospects. Outcomes of VC-funded firms in terms of firm size and innovation are much better than those of nonVC-funded firms that are otherwise similar to VC-funded firms based on key observable characteristics. Moreover, it is not just the funding level that matters - startups that are backed by high quality venture capitalists achieve better outcomes even after controlling for initial funding infusion. In other words, there is considerable heterogeneity in the treatment effects associated with venture capital. ${ }^{35}$ The next section proposes a model that can account for many of the stylized facts presented so far.

\section{The Model}

Every period $s$ new entrepreneurs approach financiers to acquire funding for startups, where $s$ is exogenous. Entrepreneurs come in two ex ante types, $i \in\{h, l\}$, namely high or low. High-type entrepreneurs are more likely to develop a successful project, have a higher level of synergy with a financier, and attain a higher level of productivity than low-type entrepreneurs, other things equal. There are 2 types of financiers, $f \in\{v, n\}$; namely, venture capitalists, $v$, and non-venture capitalists, $n$, the latter corresponding to traditional financial institutions, such as banks. Out of the $s$ new startups, $s^{n}$ are financed by banks and $s^{v}$ by venture capitalists. A venture capitalist nurtures startups by providing both expertise and funding. A traditional financial institution offers a much more limited amount of expertise. In the equilibrium being modeled, $s^{v}<s$ so that not all new entrepreneurs can be financed by venture capitalists; some must go to traditional financial institutions. The analysis will focus on balanced growth paths. Specifically, aggregate productivity, $\mathbf{x}$, will grow at some endogenous gross rate, $g_{\mathbf{x}}>1$, which in turn results in wages, $w$, growing at another constant endogenous rate, $g_{w}>1$.

A successful venture is one that starts producing. Funded startups face two sources of

\footnotetext{
${ }^{35}$ This view is further supported by recent studies that directly aim to estimate the unobserved venture capitalist and match quality effects using funding duration data. For instance, Wong (2019) finds that about two-thirds of the variation in venture capital funding duration is attributable to venture capital and match-specific unobserved effects.
} 


\begin{tabular}{lcc}
\multicolumn{3}{c}{ Ex ANte MatchiNG } \\
\hline \hline Financing & \multicolumn{2}{c}{ Entrepreneurs, fraction } \\
\hline & High & Low \\
VC Funded & $\mu_{h}^{v}$ & $\mu_{l}^{v}=1-\mu_{h}^{v}$ \\
Non-VC Funded & $\mu_{h}^{n}$ & $\mu_{l}^{n}=1-\mu_{h}^{n}$ \\
\hline
\end{tabular}

Table 3: By construction the numbers in a row sum to one. The number of VC-funded startups in the ex ante high are low states are $s^{v} \mu_{h}^{v}$ and $s^{v} \mu_{l}^{v}$, while the corresponding numbers for non-VC-funded startups read $s^{n} \mu_{h}^{n}$ and $s^{n} \mu_{l}^{n}$.

uncertainty regarding success. First, a startup may fail. Second, even if it succeeds, the startup can enter either a high or low ex post state for production, represented by $j \in\{h, l\}$. An entrepreneur who begins in ex ante state $i$ and then who transits to ex post state $j$ will be referred to as type $(i, j)$. There are synergies between an entrepreneur and a financier. The synergy between a type- $f$ financier and a type- $(i, j)$ entrepreneur is represented by $z_{i j}^{f}$, for $f=v, n$ and $i, j=h, l$. A reasonable conjecture might be that venture capitalists provide more nurturing for startups. Hence, it should transpire that $z_{i j}^{v}>z_{i j}^{n}$ for $i, j=h, l$. Additionally, because the high states are better than the low ones, it might be reasonable to presume that $z_{h j}^{f}>z_{l j}^{f}$ and $z_{i h}^{f}>z_{i l}^{f}$, for $f=v, n$. The $z$ 's will be estimated in Section 6 , so the validity of these suppositions can be examined.

The matching process between entrepreneurs and financiers is a random process, and potentially assortative in nature. The fraction $\mu_{h}^{v}$ of the projects financed by venture capitalists are with ex ante high-type entrepreneurs, while the remaining fraction, $\mu_{l}^{v}=1-\mu_{h}^{v}$, are with low-type ones. The corresponding fractions for non-VC funding are given by $\mu_{h}^{n}$ and $\mu_{l}^{n}=1-\mu_{h}^{n}$. The matching process is summarized by Table 3 . There is positive assortative matching when $\mu_{h}^{v}>\mu_{h}^{n}$, which turns out to be the case in the U.S. data-based on the statistical tests done in Section 2.2 and Table 1.

\subsection{Successful Ventures}

The output, $o_{i j}^{f}$, of a successful ex post type- $(f, i, j)$ startup is

$$
o_{i j}^{f}=\left(x_{i j}^{f} z_{i j}^{f}\right)^{\zeta}\left(k_{i j}^{f}\right)^{\kappa}\left(l_{i j}^{f}\right)^{\lambda} \text {, with } \zeta+\kappa+\lambda=1 \text {, for } f=v, n \text { and } i, j=h, l \text {. }
$$


where $k_{i j}^{f}$ and $l_{i j}^{f}$ are the amounts of capital and labor used in production, $x_{i j}^{f}$ is the firm's level of productivity, and $z_{i j}^{f}$ is the synergy level between the entrepreneur and financier. In the analysis $x_{i j}^{f}$ will be an endogenous variable that will be a function of the amount of research the startup does. This variable will be matched up with the patenting activity of the various types of startups. There is no production in the incubation period before success occurs.

A producing firm can freely rent capital at the rate $r$ and hire labor at the wage rate $w$. It does so to maximize profits. The rental price for capital incorporates a depreciation rate of $1-\mathfrak{d}$. The profit function associated with this maximization problem is

$$
x_{i j}^{f} z_{i j}^{f}(1-\kappa-\lambda)\left[\left(\frac{\kappa}{r}\right)^{\kappa}\left(\frac{\lambda}{w}\right)^{\lambda}\right]^{1 / \zeta}=\max _{k_{i j}^{f}, l_{i j}^{f}}\left\{o_{i j}^{f}-r k_{i j}^{f}-w l_{i j}^{f}: \text { s.t. (1) }\right\}
$$

for $f=v, n$ and $i, j=h, l$. Along a balanced growth path wages will grow at some (endogenous gross) rate, $g_{w}$. As can be seen from the profit function, rising wages operate to reduce the profits of an enterprise as it ages. The present value of the profits from a successful venture in the current period is

$$
\begin{aligned}
& x_{i j}^{f} z_{i j}^{f} \sum_{t=0}^{\infty}\left(\frac{\delta \mathbf{s}}{g_{w}^{\lambda / \zeta}}\right)^{t}(1-\kappa-\lambda)\left[\left(\frac{\kappa}{r}\right)^{\kappa}\left(\frac{\lambda}{w}\right)^{\lambda}\right]^{1 / \zeta} \\
\equiv & x_{i j}^{f} z_{i j}^{f} I(\cdot), \text { for } f=v, n \text { and } i, j=h, l,
\end{aligned}
$$

where $\mathbf{s}$ is the survival rate for a firm. The value from a successful venture turns out to be linear in $x_{i j}^{f} z_{i j}^{f}$.

\section{$3.2 \quad$ Startups}

The productivity level of a type- $(f, i, j)$ startup, $x_{i j}^{f}$, is endogenous. The more ambitious a new enterprise is at the time of inception, or the higher productivity, $x_{i j}^{f}$, is relative to the current level of aggregate productivity, denoted by $\mathbf{x}$, the greater is the initial research cost. The state-specific research cost for a startup is specified by the function

$$
R\left(\frac{x_{i j}^{f}}{\mathbf{x}}\right)=w\left(\frac{x_{i j}^{f}}{\mathbf{x}}\right)^{\iota} /\left(\iota \chi_{i j}^{f}\right), \text { with } \iota>1 \text {, and for } f=v, n \text { and } i, j=h, l \text {. }
$$


The higher $\chi_{i j}^{f}$ is, the lower will be cost of research. This parameter will be estimated for the various type of startups in Section 6.

The likelihood that a startup will be successful depends upon the amount of development funding it receives. Let $\sigma_{i j}^{f}$ denote the odds that a type- $(f, i, j)$ venture will be successful. These odds can be secured with a funding level of $D\left(\sigma_{i j}^{f}\right)$, where

$$
D\left(\sigma_{i j}^{f}\right)=w\left(\frac{1}{1-\sigma_{i j}^{f}}-1\right) \sigma_{i j}^{f} / \psi_{i j}^{f}, \text { for } f=v, n \text { and } i, j=h, l
$$

The cost of developing a project drops with $\psi_{i j}^{f}$. This parameter will also be estimated a type- $(f, i, j)$ startup in Section 6 .

$\mathrm{R} \& \mathrm{D}$ is done separately for each ex post state, $j=h, l$, before the realization of the state is known. A type $(f, i)$ startup will only enter the ex post high state, $h$, with the productivity/synergy combination $x_{i h}^{f}$ and $z_{i h}^{f}$, with probability $\sigma_{i h}^{f}<1$. So, a contingency plan for the low state, $l$, is also developed. Of course, an all or nothing strategy for the high state could be pursued, which would involve setting $x_{i l}^{f}=\sigma_{i l}^{f}=0$, but this will never be done. The entrepreneur must seek outside funding to cover these R\&D startup costs, $R\left(x_{i h}^{f} / \mathbf{x}\right)+D\left(\sigma_{i h}^{f}\right)+R\left(x_{i l}^{f} / \mathbf{x}\right)+D\left(\sigma_{i l}^{f}\right)$, where again there are two mutually exclusive sources for startup funding, $f=v, n$.

\section{Decision Problems}

\subsection{VC-Financed Startups}

Suppose that an ex ante type- $i$ entrepreneur receives funding and mentoring from a venture capitalist. The entrepreneur and the venture capitalist sign a contract, which stipulates that the entrepreneur must pay the venture capitalist $p_{i h}^{v}$ if the project is successful in the high state and $p_{i l}^{v}$ if it lands in the low state. The probabilities of success in the high and low states, $\sigma_{i h}^{f}$ and $\sigma_{i l}^{f}$, are also specified by the contract, as are the productivities, $x_{i h}^{v}$ and $x_{i l}^{v}$. 
The terms of the agreement are prescribed by the following Nash Bargaining problem

$$
\begin{aligned}
\max _{\sigma_{i h}^{v}, \sigma_{i l}^{v}, x_{i h}^{v}, x_{i l}^{v}, p_{i h}^{v}, p_{i l}^{v}}\left[\sigma_{i h}^{v} \delta x_{i h}^{v} z_{i h}^{v} I\left(.^{\prime}\right)+\sigma_{i l}^{v} \delta x_{i l}^{v} z_{i l}^{v} I\left(.^{\prime}\right)-\sigma_{i h}^{v} \delta p_{i h}^{v}-\sigma_{i l}^{v} \delta p_{i l}^{v}-E_{i}\right] \\
\times\left[\sigma_{i h}^{v} \delta p_{i h}^{v}+\sigma_{i l}^{v} \delta p_{i l}^{v}-R\left(\frac{x_{i h}^{v}}{\mathbf{x}}\right)-R\left(\frac{x_{i l}^{v}}{\mathbf{x}}\right)-D\left(\sigma_{i h}^{v}\right)-D\left(\sigma_{i l}^{v}\right)-V\right],
\end{aligned}
$$

where $E_{i}$ and $V$ are the threat points of the entrepreneur and the venture capitalist, respectively. ${ }^{36}$ Here $\delta$ is the market discount factor, or the reciprocal of the risk-free gross interest rate on saving and lending by consumers. This is used to discount the payoffs to both parties for each ex post state $j=h, l$. The term in brackets on the first line presents the expected reward to the entrepreneur, net of his threat point, while the term on the second line gives the same thing for the venture capitalist.

The upshot of the above Nash Bargaining problem is the following three first-order conditions:

$$
\begin{gathered}
\delta x_{i j}^{v} z_{i j}^{v} I\left(\cdot^{\prime}\right)=D_{1}\left(\sigma_{i j}^{v}\right), \text { for } j=h, l, \\
\delta \sigma_{i j}^{v} z_{i j}^{v} I\left(\cdot^{\prime}\right)=R_{1}\left(\frac{x_{i j}^{v}}{\mathbf{x}}\right) / \mathbf{x}, \text { for } j=h, l,
\end{gathered}
$$

and

$$
\begin{aligned}
\sigma_{i h}^{v} \delta p_{i h}^{v}+\sigma_{i l}^{v} \delta p_{i l}^{v}=R\left(\frac{x_{i h}^{v}}{\mathbf{x}}\right)+ & R\left(\frac{x_{i l}^{v}}{\mathbf{x}}\right)+D\left(\sigma_{i h}^{v}\right)+D\left(\sigma_{i l}^{v}\right) \\
+ & \frac{1}{2}\left[\sigma_{i h}^{v} \delta x_{i h}^{v} z_{i h}^{v} I\left(\cdot^{\prime}\right)+\sigma_{i l}^{v} \delta x_{i l}^{v} z_{i l}^{v} I\left(\cdot^{\prime}\right)\right. \\
& \left.\quad-R\left(\frac{x_{i h}^{v}}{\mathbf{x}}\right)-R\left(\frac{x_{i l}^{v}}{\mathbf{x}}\right)-D\left(\sigma_{i h}^{v}\right)-D\left(\sigma_{i l}^{v}\right)+V-E_{i}\right] .
\end{aligned}
$$

The first condition implies that the probability of success for each ex post state $j$ is chosen in the first-best manner. A marginal increase in the state- $j$ success probability, $\sigma_{i j}^{v}$, raises the discounted value of a successful venture by $\delta x_{i j}^{v} z_{i j}^{v} I\left(\cdot^{\prime}\right)$, which is the marginal benefit.

\footnotetext{
${ }^{36}$ Silveira and Wright (2016) build a canonical search model of the process where entrepreneurs are matched with venture capitalists. Upon meeting, the parties bargain in Nash fashion over each one's investment and how to split the proceeds. Their analysis is entirely theoretical in nature and does not focus on the process of innovation and growth.
} 
Development costs move up by $D_{1}\left(\sigma_{i j}^{v}\right)$, which represents the marginal cost. So, the marginal benefit from increasing $\sigma_{i j}^{v}$ equals its marginal cost. The next condition sets for each state $j$ the discounted expected marginal benefit from an increment in productivity, $\delta \sigma_{i j}^{v} z_{i j}^{v} I\left(\cdot^{\prime}\right)$, equal to the marginal cost of research, $R_{1}\left(x_{i j}^{v} / \mathbf{x}\right) / \mathbf{x}$. Thus, $x_{i j}^{v}$ is also set in a first best manner. The third condition specifies the venture capitalist's expected discounted payment, $\sigma_{i h}^{v} \delta p_{i h}^{v}+\sigma_{i l}^{v} \delta p_{i l}^{v}$. It is equal to his R\&D startup costs, $R\left(x_{i h}^{v} / \mathbf{x}\right)+R\left(x_{i l}^{v} / \mathbf{x}\right)+D\left(\sigma_{i h}^{v}\right)+D\left(\sigma_{i l}^{v}\right)$, plus one half of the expected surplus, net of the difference in threat points, or $\left[\sigma_{i h}^{v} \delta x_{i h}^{v} z_{i h}^{v} I\left(\cdot^{\prime}\right)+\right.$ $\left.\sigma_{i l}^{v} \delta x_{i l}^{v} z_{i l}^{v} I\left(\cdot^{\prime}\right)-R\left(x_{i h}^{v} / \mathbf{x}\right)-R\left(x_{i l}^{v} / \mathbf{x}\right)-D\left(\sigma_{i h}^{v}\right)-D\left(\sigma_{i l}^{v}\right)+V-E_{i}\right] / 2 .{ }^{37}$ The upshot of the first two conditions is summarized by the following lemma.

Lemma 1 (The Impact of Synergy) The higher the ex post state-j synergy, $z_{i j}^{v}$, between an ex ante type-i entrepreneur and the venture capitalist, the more ambitious a project will be as reflected by:

1. a higher level of productivity, $x_{i j}^{v}$;

2. a higher likelihood of success, $\sigma_{i j}^{v}$; and

3. a higher level of funding, $R\left(x_{i j}^{v} / \mathbf{x}\right)+D\left(\sigma_{i j}^{v}\right)$,

for $j=h, l$.

Proof. See Appendix 12.

Now, an ex ante type- $i$ entrepreneur can always go to a bank for funding. So, his threat point, $E_{i}$, is given by maximized value of the bank startup problem (P2) presented below. Now, suppose that a venture capitalist has only one draw in the matching scenario. Then he will have no outside option. Thus, his threat point is given by $V=0$. Therefore, the venture capitalist's expected profits from a contract with ex ante type- $i$ entrepreneur, $V_{i}$, are

$$
V_{i}=\left[\sigma_{i h}^{v} \delta x_{i h}^{v} z_{i h}^{v} I\left(\cdot^{\prime}\right)+\sigma_{i l}^{v} \delta x_{i l}^{v} z_{i l}^{v} I\left(\cdot^{\prime}\right)-R\left(x_{i h}^{v} / \mathbf{x}\right)-R\left(x_{i l}^{v} / \mathbf{x}\right)-D\left(\sigma_{i h}^{v}\right)-D\left(\sigma_{i l}^{v}\right)-E_{i}\right] / 2,
$$

\footnotetext{
${ }^{37}$ Jovanovic and Szentes (2013) build a model of venture capital that focuses on characterizing and measuring the excess returns earned by venture capitalists, due to the latters' scarcity. Their analysis abstracts from innovation and growth.
} 
which represents half of the surplus from the enterprise net of the entrepreneur's threat point. ${ }^{38}$

\subsection{Non-VC-Financed Startups}

A banker lends to an ex ante type- $i$ entrepreneur at the market discount factor $i_{i}$ (which is the reciprocal of the gross interest rate). This discount factor differs by a startup's ex ante type, $i$, and takes into account that the startup might fail with probability $1-\sigma_{i h}^{n}-$ $\sigma_{i l}^{n}$. When a startup fails, the entrepreneur defaults on the loan's interest and principal, $\left[D\left(\sigma_{i h}^{n}\right)+R\left(x_{i h}^{n} / \mathbf{x}\right)+D\left(\sigma_{i l}^{n}\right)+R\left(x_{i l}^{n} / \mathbf{x}\right)\right] / i_{i}$. The gross interest rate charged by banks, $1 / i_{i}$, will be determined by a zero-profit constraint for bankers. If bankers can raise funds at the risk-free rate $1 / \delta$, then

$$
\frac{\sigma_{i h}^{n}+\sigma_{i l}^{n}}{i_{i}}=\frac{1}{\delta} \text { or } \frac{1}{i_{i}}=\frac{1}{\delta\left(\sigma_{i h}^{n}+\sigma_{i l}^{n}\right)} .
$$

Therefore, the gross interest rate charged by banks, $1 / i_{i}$, is decreasing in the success probability, $\sigma_{i h}^{n}+\sigma_{i l}^{n}$. Equivalently, the gross interest rate is increasing in the failure rate, $1-\sigma_{i h}^{n}-\sigma_{i l}^{n}$. Clearly, $1 / i_{i}>1 / \delta$ or $i_{i}<\delta$.

Now, the entrepreneur's maximization problem is

$$
\begin{aligned}
E_{i}= & \max _{\sigma_{i h}^{n}, \sigma_{i l}^{n}, x_{i h}^{n}, x_{i l}^{n}} \delta\left\{\sigma_{i h}^{n} x_{i h}^{n} z_{i h}^{n} I\left(\cdot^{\prime}\right)+\sigma_{i l}^{n} x_{i l}^{n} z_{i l}^{n} I\left(\cdot^{\prime}\right)\right. \\
& \left.-\left(\sigma_{i h}^{n}+\sigma_{i l}^{n}\right)\left[R\left(\frac{x_{i h}^{n}}{\mathbf{x}}\right)+R\left(\frac{x_{i l}^{n}}{\mathbf{x}}\right)+D\left(\sigma_{i h}^{n}\right)+D\left(\sigma_{i l}^{n}\right)\right] / i_{i}\right\},
\end{aligned}
$$

subject to (7). Here the entrepreneur takes into account how his business plan for the startup influences the gross interest rate that he pays. The two sets of first-order conditions associated with the above maximization problem are:

$$
\delta x_{i j}^{n} z_{i j}^{n} I\left(\cdot^{\prime}\right)=D_{1}\left(\sigma_{i j}^{n}\right), \text { for } j=h, l,
$$

\footnotetext{
${ }^{38}$ The division of profits between the entrepreneur and venture capitalist plays no role in the analysis. As can be seen from the first-order conditions (4) and (5), the division of profits doesn't affect the choices for $\sigma_{i j}^{v}$ and $x_{i j}^{v}$.
} 
and

$$
\delta \sigma_{i j}^{n} z_{i j}^{n} I\left(\cdot^{\prime}\right)=R_{1}\left(\frac{x_{i j}^{n}}{\mathbf{x}}\right) / \mathbf{x}, \text { for } j=h, l
$$

These two efficiency conditions for $\sigma_{i j}^{n}$ and $x_{i j}^{n}$ have the same generic form as (4) and (5). The values for $\sigma_{i j}^{n}$ and $x_{i j}^{n}$ will differ from $\sigma_{i j}^{v}$ and $x_{i j}^{v}$ for two reasons. First, $z_{i j}^{n} \neq z_{i j}^{v}$. Second, the cost functions for research and development differ; i.e., within the $R$ and $D$ functions, $\chi_{i j}^{n} \neq \chi_{i j}^{v}$ and $\psi_{i j}^{n} \neq \psi_{i j}^{v}$. This will discussed further in Section 6 .

\section{Balanced Growth}

To start with, denote the gross growth rate for aggregate productivity, or $\mathbf{x}$, by $g_{\mathbf{x}} \equiv \mathbf{x}^{\prime} / \mathbf{x}$. Define the average level of productivity for a type- $f$ financed venture in the ex post high state, $j=h$, by

$$
x_{h}^{f}=\left(\mu_{h}^{f} \sigma_{h h}^{f} x_{h h}^{f}+\mu_{l}^{f} \sigma_{l h}^{f} x_{l h}^{f}\right) /\left(\mu_{h}^{f} \sigma_{h h}^{f}+\mu_{l}^{f} \sigma_{l h}^{f}\right), \text { for } f=n, v \text {. }
$$

The fractions of all successful startups in the high state that have type- $f$ funding are

$$
\nu_{h}^{f}=\frac{s^{f}\left(\mu_{h}^{f} \sigma_{h h}^{f}+\mu_{l}^{f} \sigma_{l h}^{f}\right)}{s^{v}\left(\mu_{h}^{v} \sigma_{h h}^{v}+\mu_{l}^{v} \sigma_{l h}^{v}\right)+s^{n}\left(\mu_{h}^{n} \sigma_{h h}^{n}+\mu_{l}^{n} \sigma_{l h}^{n}\right)}, \text { for } f=n, v \text {. }
$$

In a similar vein, the average level of productivity over all startups in the ex post low state, $j=l$, is given by

$$
x_{l}=\frac{s^{v}\left(\mu_{h}^{v} \sigma_{h l}^{v} x_{h l}^{v}+\mu_{l}^{v} \sigma_{l l}^{v} x_{l l}^{v}\right)+s^{n}\left(\mu_{h}^{n} \sigma_{h l}^{n} x_{h l}^{n}+\mu_{l}^{n} \sigma_{l l}^{n} x_{l l}^{n}\right)}{s^{v}\left(\mu_{h}^{v} \sigma_{h l}^{v}+\mu_{l}^{v} \sigma_{l l}^{v}\right)+s^{n}\left(\mu_{h}^{n} \sigma_{h l}^{n}+\mu_{l}^{n} \sigma_{l l}^{n}\right)} .
$$

Next, define the following growth factors for the above three ex post classes of enterprises

$$
g_{h}^{f} \equiv \frac{x_{h}^{f}}{\mathbf{x}}, \text { for } f=v, n, \text { and } g_{l} \equiv \frac{x_{l}}{\mathbf{x}}
$$

The $g$ 's are determined by the choice problems (P1) and (P2), and must be constant along a balanced growth path. For this to be the case, the $x_{i j}^{f}$ 's have to grow over time at the same rate as $\mathbf{x}$. Additionally, the $\sigma_{i j}^{f}$ 's must be constant. Can a balanced growth path exist where 
entrepreneurs are choosing different levels of innovation? If so, what determines the growth rate for the aggregate level of productivity, $g_{\mathbf{x}}$ ?

Now, suppose that the aggregate level of productivity in the current period, $\mathbf{x}$, reflects the average productivities of each of the above three classes of enterprises as well as their mass in the set of producing startups. Specifically, let $\mathbf{x}^{\prime}$ read

$$
\mathbf{x}^{\prime}=c\left(\nu_{h}^{v} x_{h}^{v}\right)^{\gamma_{h}^{v}}\left(\nu_{h}^{n} x_{h}^{n}\right)^{\gamma_{h}^{n}}\left(\nu_{l} x_{l}\right)^{1-\gamma_{h}^{v}-\gamma_{h}^{n}}
$$

where $c$ is a constant term and $0<\gamma_{h}^{v}, \gamma_{h}^{n}, \gamma_{h}^{v}+\gamma_{h}^{n}<1$. This law of motion depends upon both the extensive (the $\nu$ 's) and intensive (the $x$ 's) margins of the three ex post categories of startups. The aggregate level of productivity's gross growth rate, $g_{\mathbf{x}}$, will be

$$
\begin{aligned}
g_{\mathbf{x}} & \equiv \frac{\mathbf{x}^{\prime}}{\mathbf{x}}=\frac{c\left(\nu_{h}^{v} x_{h}^{v}\right)_{h}^{v}\left(\nu_{h}^{n} x_{h}^{n}\right)^{\gamma_{h}^{n}}\left(x_{l}\right)^{1-\gamma_{h}^{v}-\gamma_{h}^{n}}}{\mathbf{x}} \\
& =c\left(\nu_{h}^{v} g_{h}^{v}\right)^{\gamma_{h}^{v}}\left(\nu_{h}^{n} g_{h}^{n}\right)^{\gamma_{h}^{n}}\left(g_{l}\right)^{1-\gamma_{h}^{v}-\gamma_{h}^{n}} .
\end{aligned}
$$

because $g_{h}^{v} \equiv x_{h}^{v} / \mathbf{x}, g_{h}^{n} \equiv x_{h}^{n} / \mathbf{x}$, and $g_{l} \equiv x_{l} / \mathbf{x}$. Therefore, the gross growth rate in the aggregate level of productivity, or $g_{\mathbf{x}}$, is just a geometric average of the average rates of innovation by each type of enterprise, or the $g$ 's, weighted by their respective masses, the $\nu$ 's. The extent to which high-type VC-funded enterprises propel the economy forward is governed by $g_{h}^{f}, \gamma_{h}^{f}$, and $\nu_{h}^{f}$, for $f=\nu, n$.

Next, the market discount factor, $\delta$, is given by

$$
\delta=\beta / g_{\mathbf{x}}^{\rho \zeta /(\zeta+\lambda)}
$$

where $\beta$ is the representative agent's subjective discount factor and $\rho$ is the coefficient of relative aversion. ${ }^{39}$ If the depreciation factor on capital is $\mathfrak{d}$, then the rental rate, $r$, will be

\footnotetext{
${ }^{39}$ That is, in the background there is a representative consumer/worker who inelastically supplies one unit of labor and has a lifetime utility function (in period 1) of the form

$$
\sum_{t=1}^{\infty} \beta^{t-1} c_{t}^{1-\rho} /(1-\rho)
$$
}

where $c_{t}$ is his consumption in period $t$. 
given by

$$
r=1 / \delta-\mathfrak{d} .
$$

How is the wage rate determined in general equilibrium and at what gross rate will it grow along a balanced growth path? To address this question, first note that there are eight types of enterprises producing: viz., ex ante high- and low-type startups that evolve into ex post high- and low-type firms, which were initially financed by venture capitalists and non-venture capitalists. Recall that each period there are $s^{v}$ firms funded by VC and $s^{n}$ by non-VC sources. Let $\#_{i j}^{f}$ refer to the number of current startups that will turn into type- $(f, i, j)$ enterprises in the subsequent period. It can be deduced that

$$
\#_{i j}^{f}=\sigma_{i j}^{f} s^{f} \mu_{i}^{f}, \text { for } f=v, n \text { and } i, j=h, l .
$$

Now, the survival rate for an operating firm is $\mathbf{s}$. Thus, the numbers of $t$-period-old type$(f, i, j)$ enterprises that will still be around are

$$
\#_{i j, t}^{f}=\mathbf{s}^{t} \#_{i j}^{f}, \text { for } f=v, n ; i, j=h, l ; \text { and } t=0,1, \cdots .
$$

Here, an age- 0 enterprise is one that just starts producing in the current period.

Next, the generic demand for labor by a type- $(f, i, j)$ enterprise, arising from the firstorder condition for labor, is

$$
l_{i j}^{f}=\left(\frac{\kappa}{r}\right)^{\kappa / \zeta}\left(\frac{\lambda}{w}\right)^{(\zeta+\lambda) / \zeta} x_{i j}^{f} z_{i j}^{f}, \text { for } f=v, n \text { and } i, j=h, l .
$$

Hence, the labor demanded by an enterprise that came on line $t$ periods ago is

$$
l_{i j, t}^{f}=\left(\frac{\kappa}{r}\right)^{\kappa / \zeta}\left(\frac{\lambda}{w}\right)^{(\zeta+\lambda) / \zeta} \frac{x_{i j}^{f}}{g_{\mathbf{x}}^{t+1}} z_{i j}^{f}=\frac{l_{i j}^{f}}{g_{\mathbf{x}}^{t+1}},
$$

since $x_{i j, t}^{f}=x_{i j}^{f} / g_{\mathbf{x}}^{t+1}$. Thus, the total demand for labor by type- $(f, i, j)$ enterprises reads

$$
\sum_{t=0}^{\infty} \#_{i j, t}^{f} l_{i j, t}^{f}=\sum_{t=0}^{\infty} \mathbf{s}^{t} \#_{i j}^{f} \frac{l_{i j}^{f}}{g_{\mathbf{x}}^{t+1}}=\frac{\#_{i j}^{f} l_{i j}^{f}}{g_{\mathbf{x}}\left(1-\mathbf{s} / g_{\mathbf{x}}\right)} .
$$


The labor-market clearing condition appears as

$$
\sum_{f=v, n} \sum_{i=h, l} \sum_{j=h, l} \frac{\#_{i j}^{f} l_{i j}^{f}}{g_{\mathbf{x}}\left(1-\mathbf{s} / g_{\mathbf{x}}\right)}=1
$$

Therefore, the solution for wages is given by

$$
w=\lambda\left(\frac{\kappa}{r}\right)^{\kappa /(\zeta+\lambda)}\left[\frac{\sum_{f=v, n} \sum_{j=h, l} \sum_{j=h, l} \#_{i j}^{f} z_{i j}^{f} x_{i j}^{f}}{g_{\mathbf{x}}\left(1-\mathbf{s} / g_{\mathbf{x}}\right)}\right]^{\zeta /(\zeta+\lambda)} \mathbf{x}^{\zeta /(\zeta+\lambda)} .
$$

Focus on the right-hand side of the above equation. Along a balanced growth path, the $\#_{i j}^{f}$ 's, $x_{i j}^{f}$ 's, $z_{i j}^{f}$ 's, and $g_{\mathbf{x}}$ will all be constant. The only thing growing is $\mathbf{x}$. Therefore, wages grow at the gross rate

$$
g_{w}=\left(\frac{\mathbf{x}^{\prime}}{\mathbf{x}}\right)^{\zeta /(\zeta+\lambda)}=g_{\mathbf{x}}^{\zeta /(\zeta+\lambda)} .
$$

The gist of the above discussion is summarized by the definition below.

Definition 1 (Balanced Growth) The following characterizes a balanced growth path:

1. RED by VC-backed startups, or $\sigma_{i j}^{f}$ and $x_{i j}^{f}$ for $i, j=h, l$, is determined by the Nash Bargaining problem (P1), taking as given $\delta, E_{i}, r, w, g_{w}, V$, and $\mathbf{x}$.

2. REDD by non-VC-backed startups, or $\sigma_{i j}^{n}$ and $x_{i j}^{n}$ for $i, j=h, l$, and the threat point for entrepreneurs, $E_{i}$, solve the bank finance problem (P2), taking as given $\delta, i, r, w, g_{w}$, and $\mathbf{x}$.

3. The wage rate, $w$, clears the labor market in accordance with (17), taking as given $\sigma_{i j}^{f}$, $x_{i j}^{f}$, and $s_{f}$, for $f=v, n$ and $i, j=h, l$, and $g_{\mathbf{x}}$. The gross growth rate in wages, $g_{w}$, is pinned by (18) given $g_{\mathbf{x}}$.

4. The market discount factor, $\delta$, and the rental rate on capital, $r$, are specified by (15) and (14), assuming a value for $g_{\mathbf{x}}$. The gross interest rate on bank loans, $1 / i_{i}$, is determined by (7), conditional on values for $\delta, \sigma_{i h}^{n}$, and $\sigma_{i l}^{n}$.

5. The threat point for a venture capitalist is simply $V=0$.

6. Aggregate productivity, $\mathbf{x}$, and its gross growth rate, $g_{\mathbf{x}}$, are specified by (12) and (13). 
From the above analysis of the balanced growth path, it can be seen that a corporate income tax will have no impact on economic growth. This transpires because it acts as

an equiproportionate reduction in all synergies, or on the $z_{i j}^{f}$ 's. This operates in the same manner as a once-and-for-all reduction in aggregate productivity.

Lemma 2 (Neutrality of a Uniform Corporate Income Tax on Long-Run Growth) Suppose the government levies a corporate income tax at rate $\tau$ on all producing enterprises, with all revenue is rebated back to consumers/workers in the form of lump-sum taxes. There is no effect on long-run growth; i.e., on $g_{\mathbf{x}}$ and $g_{w}$.

Proof. Again, see Appendix 12.

\section{Matching the Model with U.S. Census Data}

The model is now confronted with stylized facts computed using data from the U.S. Census Bureau's LBD, the USPTO's PatentsView, and VentureXpert. The length of a period is taken to be 10 years. The baseline level of aggregate productivity, $\mathbf{x}$, can be innocuously normalized to one; hence, $\mathbf{x}=1$. Some of the parameters in model are standard in macroeconomics. These are assigned common values. Parameters unique to the current study are calibrated in the recursive fashion discussed below. The calibration procedure uses facts for the average growth rate of the U.S. economy, the number of firms per worker in the economy, and the ratio of non-VC-funded to VC-funded startups. The ex ante matching probabilities, or the four $\mu_{i}^{f}$ 's in Table 3, can be computed using data from the U.S. Census Bureau and VentureXpert. Likewise, the success odds for type- $(f, i, j)$ ventures, or the eight $\sigma_{i j}^{f}$ 's, can be calculated using the same data. For each funding source, $f$, these amount to the transition probabilities of going from ex ante state $i$ to ex post state $j$. Due to disclosure restrictions imposed by the Bureau for reasons of confidentiality, facts can only be used for the average employment of type- $(f, j)$ firms; that is, for the four observations $l_{j}^{f}=\left(\mu_{h}^{f} \sigma_{h j}^{f} l_{h j}^{f}+\mu_{l}^{f} \sigma_{l j}^{f} l_{l j}^{f}\right) /\left(\mu_{h}^{f} \sigma_{h j}^{f}+\mu_{l}^{f} \sigma_{l j}^{f}\right)$, for $f=v, n$ and $j=h, l$. (In other words, the data cannot also be categorized by the ex ante type $i$ of enterprise.) Likewise, facts can only be used for the average patenting activity of type- $(f, j)$ firms. These restrictions impose 


\begin{tabular}{lcc} 
Ex Ante Matching Probabilities $(\%)$ \\
\hline \hline Type & $\geq 90$ th & $\leq 90$ th \\
\hline VC Funded & 32.55 & 67.45 \\
Non-VC Funded & 10.64 & 89.36 \\
\hline
\end{tabular}

Table 4: The data sources are discussed in Section 2.1. A firm's type refers to whether or not it is in the top decile for employment at the time of initial VC funding. These are the $\mu_{i}^{f}$ 's used in the benchmark calibration. All figures are rounded for disclosure purposes.

some limitations on the structure that can be calibrated. Given the saturated structure of the model, there is exact identification of the parameter values unique to this study. In fact, all but one of the parameters can be pinned down using analytical expressions that connect observations to parameter values. The last parameter requires simulating the model to match a desired data target.

\subsection{Number of Startups, $s^{n}$ and $s^{v}$}

From the U.S. data the success rates for the eight types of startups are known. That is, $\sigma_{i j}^{f}$ can be assigned the value $\widetilde{\sigma}_{i j}^{f}$, for $f=v, n$ and $i, j=h, l$. A $\sim$ over a variable denotes that its value for calibration purposes can be assigned directly from U.S. Census data. Let $\pi_{j}^{f}$ represent the fraction of all initial startups that were funded by source $f$ and ended up in ex post state $j$. It can be shown that

$$
\pi_{j}^{f}=\widetilde{\mu}_{h}^{f} \widetilde{\sigma}_{h j}^{f}+\widetilde{\mu}_{l}^{f} \widetilde{\sigma}_{l j}^{f}<1, \text { for } f=v, n \text { and } j=h, l .
$$

The $\pi_{j}^{f}$ 's are known since the $\widetilde{\mu}_{i}^{f}$ 's and $\widetilde{\sigma}_{i j}^{f}$ 's are. They lie below one because most startups fail. The ex ante matching probabilities in the U.S. data are reported in Table 4. Venture capitalists fund a higher percentage of high-type firms than do other financiers - this assortative match was discussed in Section 2.2. 
In the United States the number of entrepreneurs (employer businesses) per worker is 4.3 percent. Therefore, it should transpire that

$$
\frac{s^{v}\left(\pi_{h}^{v}+\pi_{l}^{v}\right)+s^{n}\left(\pi_{h}^{n}+\pi_{l}^{n}\right)}{(1-\mathbf{s})}=0.043
$$

where $\mathbf{s}$ is the survival rate for a producing firm. Additionally, the ratio of non-VC to VCfunded startups can be calculated from the U.S. data, so that a value for $\widetilde{s^{n} / s^{v}}$ is pinned down. Hence, using the above equation

$$
\left.s^{v}=0.043 \times(1-\mathbf{s}) /\left[\left(\pi_{h}^{v}+\widetilde{\sigma}_{l}^{v}\right)+\widetilde{\left(s^{n} / s^{v}\right.}\right)\left(\pi_{h}^{n}+\pi_{l}^{n}\right)\right],
$$

This equation can be used to back out values for $s^{v}$ and $s^{n}=\left(\widetilde{s^{n} / s^{v}}\right) s^{v}$.

\subsection{Growth in Startup Productivities, the $g_{j}^{f}$ 's}

The model is calibrated so that the benchmark economy grows at 1.8 percent a year. This implies a target growth rate for aggregate productivity, $g_{\mathbf{x}}$, given by

$$
g_{\mathbf{x}}=1.018^{10 \times(\zeta+\lambda) / \zeta}
$$

Data on patent stocks is used to identify the innovation rates of firms. As discussed, stylized facts for patenting activity can only be reported at the level of type- $(f, j)$ firms; i.e., it cannot be broken down by the initial type, $i$, of the enterprise. So, the calibration procedure will impose the restriction that $x_{h j}^{f}=x_{l j}^{f} \equiv x_{j}^{f}$, for $f=v, n$ and $j=h, l$. The observed innovation rates for a type- $(f, j)$ enterprise relative to a type- $(v, h)$ firm are represented by $\widetilde{\phi}_{j}^{f}$. Then,

$$
x_{j}^{f}=\widetilde{\phi}_{j}^{f} x_{h}^{v}, \text { for }(f, j) \neq(v, h) .
$$

The spillover parameters, or the $\gamma_{j}^{f}$ 's, are computed from the shares of type- $(f, j)$ firms in total patent citations. The distribution of patent citations by firm type in the United States is displayed in Table 5. On this account, $\widetilde{\gamma}_{h}^{v}=0.2622$ and $\widetilde{\gamma}_{h}^{n}=0.3917$. 


\begin{tabular}{lcc}
\multicolumn{3}{c}{ Patent Citations $(\%)$} \\
\hline \hline Type & $\geq 90$ th & $\leq 90 \mathrm{th}$ \\
\hline VC Funded & 26.22 & 2.67 \\
Non-VC Funded & 39.17 & 31.93 \\
\hline
\end{tabular}

Table 5: Again, the data sources are discussed in Section 2.1. A firm's type refers to whether or not it is in the top decile for employment 10 years after VC funding. The first column gives the numbers used for $\gamma_{h}^{v}$ and $\gamma_{h}^{n}$. All figures are rounded for disclosure purposes.

From equation (13) it then follows that

$$
g_{\mathbf{x}}=c x_{h}^{v}\left(\nu_{h}^{v}\right)^{\widetilde{\gamma}_{h}^{v}}\left(\nu_{h}^{n} \widetilde{\phi}_{h}^{n}\right)^{\widetilde{\gamma}_{h}^{n}}\left(\widetilde{\phi}_{l}\right)^{1-\widetilde{\gamma}_{h}^{v}-\widetilde{\gamma}_{h}^{n}}
$$

where equation (10) defines $\nu_{h}^{f}$ and by using (11) it is easy to deduce that

$$
\phi_{l} \equiv \frac{s^{v}\left(\widetilde{\mu}_{h}^{v} \widetilde{\sigma}_{h l}^{v}+\widetilde{\mu}_{l}^{v} \widetilde{\sigma}_{l l}^{v}\right) \widetilde{\phi}_{l}^{v}+s^{n}\left(\widetilde{\mu}_{h}^{n} \widetilde{\sigma}_{h l}^{n}+\widetilde{\mu}_{l}^{n} \widetilde{\sigma}_{l l}^{n}\right) \widetilde{\phi}_{l}^{n}}{s^{v}\left(\widetilde{\mu}_{h}^{v} \widetilde{\sigma}_{h l}^{v}+\widetilde{\mu}_{l}^{v} \widetilde{\sigma}_{l l}^{v}\right)+s^{n}\left(\widetilde{\mu}_{h}^{n} \widetilde{\sigma}_{h l}^{n}+\widetilde{\mu}_{l}^{n} \widetilde{\sigma}_{l l}^{n}\right)} .
$$

Now, choose $c=1 /\left[\left(\nu_{h}^{v}\right)^{\tilde{\gamma}_{l}^{v}}\left(\nu_{h}^{n}\right)^{\widetilde{\gamma}_{h}^{n}}\right]$, an innocuous normalization. Then,

$$
g_{h}^{v}=x_{h}^{v}=\frac{g_{\mathbf{x}}}{\left(\widetilde{\phi}_{h}^{n}\right)^{\widetilde{\gamma}_{h}^{n}}\left(\widetilde{\phi}_{l}\right)^{1-\widetilde{\gamma}_{h}^{v}-\widetilde{\gamma}_{h}^{n}}}(\text { recall } \mathbf{x}=1)
$$

Therefore,

$$
g_{j}^{f}=\widetilde{\phi}_{j}^{f} g_{h}^{v}, \text { for }(f, j) \neq(v, h) .
$$

\subsection{Synergies, the $z_{i j}^{f}$ 's}

The relative employments of firms are used to identify the synergy parameters or the $z_{i j}^{f}$ 's. Let $\tilde{e}_{j}^{f}$ denote the observed employment of a type- $(f, j)$ firm relative to a type- $(v, h)$ one. There are four of these. As was discussed earlier, unfortunately employment cannot categorized by the ex ante type $i$ of an enterprise. Given this only four unique synergy parameters can be backed out using U.S. Census data from the calibration procedure. So, set $z_{h j}^{f}=z_{l j}^{f} \equiv z_{j}^{f}$ in the calibration procedure. The four synergy parameters, $z_{h}^{v}, z_{l}^{v}, z_{h}^{n}$, and $z_{l}^{n}$, are pinned down as follows. First, set $z_{h}^{v}=1$. Then, using the labor demand functions (16) and the data on 
relative employments, $\widetilde{e}_{j}^{f}$, the following holds

$$
\frac{x_{h}^{v} z_{h}^{v}}{x_{j}^{f} z_{j}^{f}}=\left(\frac{x_{h}^{v}}{x_{j}^{f}}\right) \frac{1}{z_{j}^{f}}=\widetilde{e}_{j}^{f},
$$

so that

$$
z_{j}^{f}=\left(\frac{x_{h}^{v}}{x_{j}^{f}}\right) / \widetilde{e}_{j}^{f}, \text { for }(f, j) \neq(v, h) .
$$

The wage rate, $w$, can be now determined at the calibration point using (17).

\subsection{The Efficiencies of Research and Development, the $\psi_{i j}^{f}$ 's, $\chi_{i j}^{f}$ 's, and $\iota$}

The desired values for the startups' productivities and success rates, $x_{i j}^{f}$ and $\sigma_{i j}^{f}$, can be achieved by backing out the constant parameters for the research and development functions, $\chi_{i j}^{f}$ 's and $\psi_{i j}^{f}$ 's, so that the model hits these targets. In particular, the first-order condition for $\sigma_{i j}^{f}$ states that

$$
\delta x_{i j}^{f} z_{i j}^{f} I\left(\cdot^{\prime}\right)=w\left[\frac{1}{\left(1-\tilde{\sigma}_{i j}^{f}\right)^{2}}-\left(\frac{1}{1-\tilde{\sigma}_{i j}^{f}}-1\right)\right] / \psi_{i j}^{f},
$$

so that

$$
\psi_{i j}^{f}=\left\{w\left[\frac{1}{\left(1-\tilde{\sigma}_{i j}^{f}\right)^{2}}-\left(\frac{1}{1-\tilde{\sigma}_{i j}^{f}}-1\right)\right]\right\} /\left[\delta x_{i j}^{f} z_{i j}^{f} I\left(\cdot^{\prime}\right)\right] .
$$

Following a similar procedure for $x_{i j}^{f}$ 's gives

$$
\chi_{i j}^{f}=w\left(\frac{x_{i j}^{f}}{\mathbf{x}}\right)^{\iota-1} /\left[\mathbf{x} \delta \widetilde{\sigma}_{i j}^{f} z_{i j}^{f} \times I\left(\cdot^{\prime}\right)\right]
$$

Since there are eight values for the $\tilde{\sigma}_{i j}^{f}$ 's, there will be eight unique value for the $\chi_{i j}^{f}$ 's and $\psi_{i j}^{f}$ 's (even though there are only four unique values for the $x_{i j}^{f}$ 's). The backed-out parameter values for $\psi_{i j}^{f}$ and $\chi_{i j}^{f}$ depend upon the elasticity parameter $\iota$ in the research cost function. The determination of $\iota$ is discussed now.

Henrekson and Sanandaji (2018) report that Canada had a tax rate on VC-funded startups of 32 percent and a VC-investment-to-GDP ratio of 0.04 percent. Their numbers for the 
United States are 15 and 0.20 percent. This implies a tax elasticity of $-\ln (0.20 / 0.04) / \ln (0.15 / 0.32)=$ 2.12. The parameter $\iota$ is fit to match this elasticity.

\subsection{The Model's Fit}

The calibration targets for the United States and the model's fit for these targets are shown in Table 7, with the parameter values used being presented in Table 6. As can be seen, over the time period in question GDP grew at 1.8 percent a year. The model matches this number. A VC-funded startup is much more likely to be highly successful than a non-VCfunded one. A VC-funded venture that starts out in the top decile of employment has a 33 percent chance of making it into the top employment decile 10 years later, as Table 7 shows. This compares with 23.77 percent of non-VC-funded firms. A VC-funded startup that begins in the bottom 90 percent of the employment distribution still has a 23.77 percent chance of making it to the top, compared with only 1.68 percent for a non-VC-funded firms. Recall from Table 4, though, that a VC-funded firm is much more likely to start out in the top decile than a non-VC-funded one; viz., 32.55 versus 10.64 percent. This is due to selection. The unconditional probabilities for VC-funded and non-VC-funded firms ending up in the high and low states are presented in Table 8. It can be seen that VC-funded firms have 26.81 and 9.06 percent chances of ending up in the high and low states, while for non-VC-funded startups the numbers are 3.58 and 31.71 percent. Conditioned on success, VC-funded firms have a much higher likelihood of winding up in the high state (74.75 percent) relative to non-funded ones (10.15 percent). The failure rates for both types of startups are very high, 64.1 and 64.7 percent.

A VC-funded startup that makes it into the top 10 percent of firms has a much higher employment than a non-VC-funded firm. The latter's employment is only 16 percent of the former's. The employment levels of both types of startups, should they end up in the bottom 90 percent, are much smaller. Still, a VC-funded firm has 1.6 times the level of employment of a non-VC-funded firm. On average a VC-funded firm has 38.02 times 
Calibrated Parameter Values

\begin{tabular}{|c|c|c|}
\hline Parameter Values & Description & Identification \\
\hline \multicolumn{3}{|l|}{ Consumers } \\
\hline$\widehat{\delta}=0.95$ & Discount factor - annualized & $7 \%$ risk-free rate \\
\hline \multicolumn{3}{|l|}{ Firms } \\
\hline$\kappa=1 / 3 \times 0.85=0.283$ & Capital's share & Standard \\
\hline$\lambda=2 / 3 \times 0.85=0.567$ & Labor's share & Standard \\
\hline $1-\mathfrak{d}=0.07$ & Depreciation rate - annualized & Standard \\
\hline $\mathbf{s}=0.96$ & Firm survival rate - annualized & Expected life of Compustat firms \\
\hline \multicolumn{3}{|l|}{ Research } \\
\hline $\begin{array}{l}\chi_{h h}^{v}=41.270, \chi_{h l}^{v}=37.540 \\
\chi_{l h}^{v}=57.49, \chi_{l l}^{v}=23.610\end{array}$ & VC Research efficiency, $x_{i j}^{v}$ & VC pat./succ. rates, U.S. data \\
\hline $\begin{array}{l}\chi_{h h}^{n}=1.616, \chi_{h l}^{n}=0.341 \\
\chi_{l h}^{n}=18.780, \chi_{l}^{n}=0.193\end{array}$ & Non-VC Research efficiency, $x_{i j}^{n}$ & Non-VC pat./succ. rates, U.S. data \\
\hline $\begin{array}{l}\chi_{l h}^{u}=18.780, \chi_{l l}^{u}=0.193 \\
\iota=3.5\end{array}$ & Research cost elasticity, $x_{i j}^{v}$ and $x_{i j}^{n}$ & Canada/U.S. Tax elasticity \\
\hline \multicolumn{3}{|l|}{ Development } \\
\hline $\begin{array}{l}\psi_{h h}^{v}=0.002, \psi_{h l}^{v}=0.042 \\
\psi_{l h}^{v}=0.001, \psi_{l l}^{v}=0.071\end{array}$ & VC Development efficiency, $\sigma_{i j}^{v}$ & VC pat./succ. rates, U.S.data \\
\hline $\begin{array}{l}\psi_{h h}^{n}=0.006, \psi_{h l}^{n}=0.249 \\
\psi_{l h}^{n}=0.000, \psi_{l l}^{n}=0.597\end{array}$ & Non-VC Development efficiency, $\sigma_{i j}^{n}$ & Non-VC pat./succ. rates, U.S. data \\
\hline \multicolumn{3}{|l|}{ Synergies } \\
\hline$z_{h}^{v}=1.00, z_{l}^{v}=0.042$ & $\mathrm{VC}$ & Empl. Ratios, U.S. data \\
\hline$z_{h}^{n}=0.801, z_{l}^{n}=0.083$ & Non-VC & \\
\hline Ex ante Matching Odds & & U.S. Data \\
\hline \multicolumn{3}{|l|}{$\mu_{h}^{v}=0.326, \mu_{l}^{v}=0.675$} \\
\hline \multicolumn{3}{|l|}{$\mu_{h}^{n}=0.106, \mu_{l}^{n}=0.894$} \\
\hline \multicolumn{3}{|l|}{ Growth Externality } \\
\hline$\gamma_{h}^{v}=0.26, \gamma_{l}^{v}=0.03$ & Exponent on VC innovation & Citation distribution, U.S. Data \\
\hline$\gamma_{h}^{n}=0.39, \gamma_{l}^{n}=0.32$ & Exponent on non-VC innovation & \\
\hline Model Period & 10 years & VC contract durations \\
\hline
\end{tabular}

Table 6: The parameter values used to replicate the data targets in Table 7. 


\section{Calibration Targets}

\begin{tabular}{|c|c|c|c|c|}
\hline Target & \multicolumn{2}{|c|}{ U.S. Data } & \multicolumn{2}{|c|}{ Model } \\
\hline Economic growth-annualized & & 1.80 & & 1.80 \\
\hline $\begin{array}{l}\text { Success Rates, } \% \text { - the } \sigma_{i j}^{f} \text { 's } \\
\text { VC funded }\end{array}$ & Top $10 \%$ & Bottom $90 \%$ & Top $10 \%$ & Bottom $90 \%$ \\
\hline ex ante top $10 \%$ & 33.11 & 6.48 & 33.11 & 6.48 \\
\hline ex ante bottom $90 \%$ & 23.77 & 10.30 & 23.77 & 10.30 \\
\hline $\begin{array}{l}\text { Non-VC funded } \\
\text { ex ante top } 10 \% \\
\text { ex ante bottom } 90 \%\end{array}$ & $\begin{array}{l}19.53 \\
1.68\end{array}$ & $\begin{array}{l}18.83 \\
33.24\end{array}$ & $\begin{array}{l}19.53 \\
1.68\end{array}$ & $\begin{array}{l}18.83 \\
33.24\end{array}$ \\
\hline $\begin{array}{l}\text { Employment, Relative } \% \text { - the } \widetilde{e}_{j}^{f} \text { 's } \\
\text { VC funded } \\
\text { Non-VC funded }\end{array}$ & $\begin{array}{c}\text { Top } 10 \% \\
100.00 \\
16.23\end{array}$ & $\begin{array}{l}\text { Bottom } 90 \% \\
0.59 \\
0.36\end{array}$ & $\begin{array}{c}\text { Top } 10 \% \\
100.00 \\
16.23\end{array}$ & $\begin{array}{l}\text { Bottom } 90 \% \\
\quad 0.59 \\
0.36\end{array}$ \\
\hline $\begin{array}{l}\text { Patenting, Relative } \% \text { - the } \widetilde{\phi}_{j}^{f} \text { 's } \\
\text { VC funded } \\
\text { Non-VC funded }\end{array}$ & $\begin{array}{c}\text { Top } 10 \% \\
100.00 \\
20.27\end{array}$ & $\begin{array}{c}\text { Bottom } 90 \% \\
14.09 \\
4.33\end{array}$ & $\begin{array}{c}\text { Top } 10 \% \\
100.00 \\
20.27\end{array}$ & $\begin{array}{c}\text { Bottom } 90 \% \\
14.09 \\
4.33\end{array}$ \\
\hline $\begin{array}{l}\text { Firms per Worker, } \% \\
\text { Ratio non-VC to VC Startups } \\
\text { Tax Elasticity }\end{array}$ & & $\begin{array}{l}4.30 \\
035.34 \\
2.1\end{array}$ & & $\begin{array}{l}4.30 \\
035.34 \\
2.05\end{array}$ \\
\hline
\end{tabular}

Table 7: See Section 2.1 for the data sources. Average employment and patent stocks are measured with respect to VC-funded firms in the top 10 percent. Patenting is measured using a quality-adjusted patent stock. Transition probabilities (the success rates) give the likelihood that an ex ante type- $i$ firm ends up as an ex post type- $j$ firm 10 years after funding, for $i, j=$ top 10 percent, bottom 90 percent.

\section{Unconditional Success Probabilities (\%)}

\begin{tabular}{lcccccc}
\hline \hline & \multicolumn{2}{c}{ By state } & By state $\sim$ failing & Overall & Failure \\
& $\pi_{j}^{f}$ & \multicolumn{2}{c}{$\pi_{j}^{f} /\left(\pi_{h}^{f}+\pi_{l}^{f}\right)$} & $\pi_{h}^{f}+\pi_{l}^{f}$ & $1-\pi_{h}^{f}+\pi_{l}^{f}$ \\
\hline Type & $\geq 90$ th & $\leq 90$ th & $\geq 90$ th & $\leq 90$ th & & \\
\hline VC Funded & 26.81 & 9.06 & 74.75 & 25.25 & 35.87 & 64.13 \\
Non-VC Funded & 3.58 & 31.71 & 10.15 & 89.85 & 35.29 & 64.71 \\
\hline
\end{tabular}

Table 8: Success probabilities when not conditioning on the initial type of startup, U.S. data and model. The figures are computed by using equation (19) and the information in Tables 4 and 7 . 


\begin{tabular}{lcc}
\multicolumn{3}{c}{ Rates of Innovation, Annualized \% } \\
\hline \hline Rate of Innovation & Top 10\% & Bottom 90\% \\
\hline VC funded & 29.23 & 6.23 \\
Non-VC funded & 10.17 & -5.59 \\
\hline
\end{tabular}

Table 9: Annualized rates of innovation for each type of firm as measured by their percentage distance from the frontier at the time of startup, $100 \times\left[\left(x_{i j}^{f} / \mathbf{x}\right)^{1 / 10}-1\right]$. All figures are rounded for disclosure purposes.

$[\cong(0.75 \times 100+0.25 \times 0.59) /(0.10 \times 16.23+0.90 \times 0.36)]$ the employment of a non-VCfunded one. Only a small number of startups are funded by venture capitalists. Specifically, there are 1,035.34 non-VC-funded startups for every VC-funded one. Yet, while VC-funded firms account for only 0.1 percent of all startups, 10 years after first funding these firms account for 3.7 percent of total employment $[\cong 0.36 \times 38.02 /(0.36 \times 38.02+1035.34 \times 0.35)]$. Hence, their punch far exceeds their weight.

Likewise, the patenting stock of a VC-funded startup in the top 10 percent of firms is much greater than that for a non-VC-funded firm. Non-VC-funded startups have only 20.27 percent of the patents that VC-funded startups have, even when they resolve into the top decile of firms. VC-funded firms in the bottom 90th percentile of firms still have 3 times the patent stocks of non-VC-funded firms. As with employment, VC-funded firms have an outsized share of innovation. Though they account for 0.1 percent of startups, they account for 1.2 percent of patenting activity ten years post funding. Last, in the United States there are 23 workers $(1 / 0.043)$ for every firm, which the model matches in addition to above statistics.

Table 9 shows that in the calibrated equilibrium most innovation in the economy is driven by VC-funded firms that make it into the top 10 percent. In fact, non-VC-funded startups that don't make it into the top decile of firms drag down the average level of productivity in the economy in the sense that even after they innovate they lag behind the aggregate level of productivity in the economy at the time of their inception. Additionally, they make up 89.77 percent of the firms in the economy, whereas VC-funded firms in the top decile comprise only 0.07 percent. 


\subsection{Interpretation of Backed-Out Parameter Values}

The backed-out parameter values are reasonable, albeit there are anomalies. As can be seen from Table 6, the synergy level between an entrepreneur and the financier is highest for VC-funded firms in the ex post high state; i.e., $z_{h}^{v}>z_{j}^{f}$, for all $(f, j) \neq(v, h)$. Also, synergy levels are always higher in the high state as opposed to the low state, $z_{h}^{f}>z_{l}^{f}$, for all $f$. The synergy between entrepreneurs and financiers is very low in the ex post low state. Somewhat surprisingly, it is lowest for VC-funded firms; i.e., $z_{l}^{v}<z_{l}^{n}$. The reason is that non-VC-funded firms in the low state do almost no innovation; i.e., their productivity level, or $x_{l}^{n}$, is very small. Therefore, to match employment for these firms, the synergy level must be raised a little to compensate - in line with calibration equation (20). Of course, VC-funded firms in the ex post low state are still better than non-VC-funded ones because $z_{l}^{v} x_{l}^{v}>z_{l}^{n} x_{l}^{n}$.

The development parameters also reveal reasonable rankings in general. First, it is more costly to achieve success in the ex post high state versus the low one. This is reflected by the fact that $\psi_{i h}^{f}<\psi_{i l}^{f}$, for all $f$ and $i$, where a higher value for $\psi$ represents a lower cost. Second, if a firm starts out in the ex ante low state, as opposed to the high state, it is harder to end up in the ex post high state; i.e., $\psi_{l h}^{f}<\psi_{h h}^{f}$, for all $f$. Still, it is more expensive for a firm starting out as a high type to achieve success in the low state as opposed to one starting out as a low-type one; that is, $\psi_{h l}^{f}<\psi_{l l}^{f}$. This occurs because the observed odds of winding up in the low state are smaller for ex ante high-type firms. Hence, the calibration procedure places a high cost on this transition — see $(21)$ — which is achieved by lowering $\psi_{h l}^{f}$ relative to $\psi_{l l}^{f}$.

Last, the research parameters look reasonable, but again there are some exceptions. First, the cost of doing research is lower for a VC-funded firm than for a non-VC-funded one; that is, $\chi_{i j}^{v} \geq \chi_{i j}^{n}$ for all $i, j$. Thus, it is easier to do research when backed by a venture capitalist, perhaps because they lend expertise. Second, for a VC-backed firm the cost of researching an ex post high idea starting out from the ex ante low state is lower than for the ex ante high state; i.e., $\chi_{l h}^{v}>\chi_{h h}^{v}$. This is an artifact of the Census data disclosure restriction on reporting patenting activity that imposed the constraint $x_{l h}^{v}=x_{h h}^{v}$, when almost certainly $x_{l h}^{v}<x_{h h}^{v}$. Now, note that $z_{l h}^{v}=z_{h h}^{v}$ and that $\sigma_{l h}^{v}<\sigma_{h h}^{v}$. Given the low success rate when starting out 
from the ex ante low state it must transpire that, to get the same level of patenting as the ex ante high state, the research costs in the ex ante low state must be lower-as (22) dictates.

\section{No Venture Capital Thought Experiment}

How important is the presence of venture capital for the economy? To answer this question, venture capital is shut down. To do this, set the synergy parameters for VC-backed enterprises equal to the ones for non-VC-backed ones, implying $z_{j}^{v}=z_{j}^{n}$. Likewise, fix the values for the research and development cost parameters for VC-funded firms to those for non-VC-funded firms; i.e., set $\chi_{i j}^{v}=\chi_{i j}^{n}$ and $\psi_{i j}^{v}=\psi_{i j}^{n}$. This renders VC-backed firms the same as non-VC-backed ones. Last, since both types of firms are the same now, in the law of motion for aggregate productivity, or equation (13), set the spillover parameter for VC-funded startups in the ex post high state equal to that of non- $\mathrm{VC}$ funded ones, so let $\gamma_{h}^{v}=\gamma_{h}^{n}$ and $\nu_{h}^{v}=\nu_{h}^{n}{ }^{40}$ This experiment is equivalent to requiring all firms to use bank financing, and shuts down all VC treatment effects on the economy.

The results of this experiment is reported in Table 10. Not surprisingly, growth falls from 1.8 percent annually to 1.30 . The drop in the growth rate derives from two key features of the baseline. First, the success rates of entering into the ex post high state for non-VC-backed startups are lower than for VC-backed ones. Second, the level of patenting activity in the high state for non-VC-backed startups is much lower than for VC-backed ones. Requiring all firms to use bank financing leads to a large welfare loss of 9.25 percent in terms of consumption.

\section{Matching Thought Experiment}

How much does the observed ex ante match between entrepreneurs and venture capitalists matter for growth? Suppose instead that there is perfect assortative matching between entrepreneurs and venture capitalists. Out of $s$ startups, $s^{n}$ are funded by banks and $s^{v}$ by

\footnotetext{
${ }^{40}$ In similar fashion, renormalize the constant term $c$ by fixing $\widetilde{\nu}_{h}^{v}=\widetilde{\nu}_{h}^{n}$.
} 
No Venture Capital Thought Experiment

\begin{tabular}{lll}
\hline \hline Variable & Baseline & No Venture Capital \\
Growth & 1.80 & 1.30 \\
C.V. & 0 & -9.25 \\
$\quad$ VC firms, high & & \\
$\quad$ fraction, $\nu_{h}^{v}$ & 0.73 & 0 \\
$\quad$ patenting, $x_{h h}^{v}$ and $x_{l h}^{v}$ & $12.99,12.99$ & $2.58^{*}, 2.57^{*}$ \\
$\quad$ success, $\sigma_{h h}^{v}$ and $\sigma_{l h}^{v}$ & $33.11,23.77$ & $19.00^{*}, 1.61^{*}$ \\
VC share of all patenting & 1.28 & 0 \\
$\quad$ Non-VC firms, high & & \\
$\quad$ fraction, $\nu_{h}^{n}$ & 99.28 & 100 \\
$\quad$ patenting, $x_{h h}^{n}$ and $x_{l h}^{n}$ & $2.63,2.63$ & $2.58,2.57$ \\
$\quad$ success, $\sigma_{h h}^{n}$ and $\sigma_{l h}^{n}$ & $19.53,1.68$ & $19.00,1.61$ \\
Non-VC share of all patenting & 98.72 & 100.00 \\
\hline
\end{tabular}

Table 10: The experiment reports what happens when venture capital is shut down. The entries with the asterisks show what VC-backed startups look like when they are degraded to resemble non-VC-backed ones. These startups are now counted as non-VC-backed ones.

venture capitalists. There will be $.1 \times s$ entrepreneurs in the top decile of projects. The situation is illustrated by the lefthand panel of Table 11. Now, the maximum number of matches between startups in the top 10 decile and venture capitalists is $\mathfrak{v} \equiv \min \left\{s^{v}, .1 \times s\right\}$, where $s=s^{n}+s^{v}$. Therefore, the probability of a venture capitalist funding a startup in the top decile is $\mathfrak{v} / s^{v}$. When venture capitalists are in short supply, as in the simulation, these odds would be 100 percent; here $\mathfrak{v}=s^{v}$ matches will occur between entrepreneurs in the top decile and venture capitalists. In general, there will be $s^{v}-\mathfrak{v}$ venture capitalists left over. They will now have to fund startups below the top decile. The odds of such a match happening are given by $\left(s^{v}-\mathfrak{v}\right) / s^{v}$. In the simulation, the pool of venture capitalists is exhausted by entrepreneurs in the top decile (because $s^{v}=\mathfrak{v}$ ). Therefore, this situation doesn't happen. Returning to the general case, there could potentially be $.1 \times s-\mathfrak{v}$ highquality entrepreneurs that are left unfunded by venture capitalists. Thus, the probability of a match between a high-quality entrepreneur and a bank is $(.1 \times s-\mathfrak{v}) / s^{n}$. Since $s^{n}$ projects will be funded by banks, they can fund $s^{n}-.1 \times s+\mathfrak{v}$ startups lying outside of the top decile. Therefore, the probability of a bank funding a low-quality entrepreneur is $\left(s^{n}-.1 \times s+\mathfrak{v}\right) / s^{n}$. 
Ex Ante Matching Probabilities

\begin{tabular}{lcccccccc}
\hline \hline & \multicolumn{2}{c}{ Data } & \multicolumn{2}{c}{ Perfect } & \multicolumn{2}{c}{ Perfect Assort. } & Random \\
\hline & \multicolumn{9}{c}{ Assortative } & with More VC \\
\hline Type & $\geq 90$ th & $\leq 90$ th & $\geq 90$ th & $\leq 90$ th & $\geq 90$ th & $\leq 90$ th & $\geq 90$ th & $\leq 90$ th \\
\hline VC Funded & 32.55 & 67.45 & 100.00 & 0 & 100.00 & 0 & 10.00 & 90.00 \\
Non-VC Funded & 10.64 & 89.36 & 9.91 & 90.09 & 0 & 100.00 & 10.00 & 90.00 \\
\hline
\end{tabular}

Table 11: The ex ante matching probabilities observed in the data (first panel), when matching is perfectly assortative (second panel), perfectly assortative matching with an increased supply of venture capitalists (third panel), and completely random (last panel). The numbers used are reported as percentages.

The movement to perfect assortative matching increases growth from 1.80 to 1.96 percentsee the second panel of Table 12. Virtually all of the uptick in growth derives from a movement along the extensive margin. That is, from an increase in the fraction of VC-funded firms that are operating in the ex post high state. This fraction moves up from 0.73 to 0.91 percent. This is partially offset by a decline in the fraction of non-VC-funded firms producing in this state. The percentage increase in VC-funded firms is however much larger. Effectively, the number of non-VC-funded firms barely moves from its baseline. Observe that the success and patenting rates increase a little. This occurs because in equilibrium the wage rate drops slightly. So, the increase in growth comes from an increase in the fraction of firms in the high state that are funded by venture capitalists. The contribution of VC firms to patenting activity also rises from 1.28 to 1.55 percent. This increase has a noticeable impact on growth due to the sizeable spillover coefficient, $\gamma_{h}^{v}$, on VC-funded firm patenting activity in the high state. While the increase in growth might seem modest, it leads to a significant welfare gain as measured by the compensating variation for a move from the baseline economy to the one with perfect assortative matching. A person would be willing to give up 2.73 percent of his consumption in each and every period along a balanced growth path in the new regime in order to effect the move, at least when assuming logarithmic utility (and when the initial level of consumption in both regimes is assumed to be the same.)

Recall that venture capitalists are in short supply in the baseline equilibrium. Now, suppose that one could increase the supply of venture capitalists so that all firms in the top decile could be funded by VC. The third panel of Table 11 shows the resulting matching probabilities. Growth would now pick up from 1.80 to 2.05 percent, which would be worth 
4.41 percent in terms of consumption-the third panel of Table 12. One might have expected an even larger welfare gain, but the impact is dampened due to a rise in wages in general equilibrium. This is reflected in the lower levels of patenting and success rates for both VCand non-VC-financed firms. So, all of the uptick in growth comes from the fact that more firms are financed by venture capitalists. VC-funded firms have higher levels of patenting and success rates than non-VC-funded firms, which allows growth to rise.

The relatively large gains in growth when matching becomes perfectly assortative suggests that policies that increase the degree of assortative matching can enhance growth. An example of such a policy is early-stage R\&D subsidies to startups. Recent evidence on the effectiveness of Small Business Innovation and Research (SBIR) grants by the federal government suggests that an important function of these grants is to allow startups to develop a "prototype" and demonstrate the feasibility of their technology or product. This demonstration can reduce uncertainty about the viability of a startup, and make it more attractive to private investment. For instance, Howell (2017) finds that a Phase I SBIR grant nearly doubles the likelihood of VC investment in a startup. In other words, such grants can act like a "match-maker" and allow startups that may otherwise be unnoticed by venture capitalists to be selected and funded by them. Making such grants available to a broader set of startups or raising the grant amount can therefore increase the degree of assortative matching, leading to higher growth.

Alternatively, suppose that matching is random - that is, selection by venture capitalists is eliminated. The situation is given by the last panel of Table 12 . There are $s^{v}$ venture capitalists in total. With random matching, $.1 \times s^{v}$ venture capitalists will be matched with firms in the top 10 percent, the rest with firms in the bottom 90 percent. Growth and welfare now drop, but ever so slightly — see Table 12. This occurs primarily from a fall in the number of VC-funded firms operating in the high state from 0.73 to 0.68 percent. The movement from the matching structure observed in the data to the random matching structure is much smaller than moving to perfect assortative matching, as can be seen in Table $11 .^{41}$ So, the

\footnotetext{
${ }^{41}$ The magnitude of these movements can be assessed using a matrix distance metric. For instance, based on the Frobenius norm, the distance between two matrices $A$ and $B$ is given by $\sqrt{\sum_{(i, j)}\left(a_{i j}-b_{i j}\right)^{2}}$, where $a_{i j}$
} 
Matching Thought Experiment

\begin{tabular}{lllll}
\hline \hline & Baseline & $\begin{array}{l}\text { Perfect } \\
\text { Assortative }\end{array}$ & $\begin{array}{l}\text { Perfect Assort. } \\
\text { with More VC }\end{array}$ & Random \\
Variable & & 1.96 & 2.05 & 1.78 \\
Growth & 1.80 & 2.73 & 4.41 & -0.27 \\
C.V. firms, high & 0 & & & \\
$\quad$ fraction, $\nu_{h}^{v}$ & 0.73 & 0.91 & 78.43 & 0.68 \\
$\quad$ patenting, $x_{h h}^{v}$ and $x_{l h}^{v}$ & $12.99,12.99$ & $13.13,13.15$ & $8.35,7.89$ & $13.06,13.07$ \\
$\quad$ success, $\sigma_{h h}^{v}$ and $\sigma_{l h}^{v}$ & $33.11,23.77$ & $33.56,24.18$ & $17.94,11.18$ & $33.12,23.78$ \\
VC share of all patenting & 1.28 & 1.5 & 69.87 & 1.20 \\
Non-VC firms, high & & & & \\
$\quad$ fraction, $\nu_{h}^{n}$ & 99.28 & 99.09 & 21.57 & 99.32 \\
$\quad$ patenting, $x_{h h}^{n}$ and $x_{l h}^{n}$ & $2.63,2.63$ & $2.67,2.68$ & $1.56,1.38$ & $2.55,2.57$ \\
$\quad$ success, $\sigma_{h h}^{n}$ and $\sigma_{l h}^{n}$ & $19.53,1.68$ & $19.91,1.73$ & $8.59,0.55$ & $19.72,1.71$ \\
Non-VC share of all patenting & 98.72 & 98.5 & 30.13 & 98.8 \\
\hline
\end{tabular}

Table 12: The experiments report what happens when the initial matching between entrepreneurs and financiers is perfect assortative, perfect assortative with an increased supply of venture capitalists, and random. All rates are reported as percentages.

impact on growth and welfare from random matching is more muted than the impact on growth from perfect assortative matching.

\section{The Taxation of Startups}

The model can be used to assess the role of the differential taxation of VC-funded startups compared to others. In the United States VC-funded startups are taxed when they are floated or sold at the capital gains rate, currently 17 percent. This happens because the key officers of the companies are remunerated in the form of stock options and/or preferred shares that only attain value when the firm goes public or is bought by another company. Other forms of startups are taxed at either the corporate or personal income tax rates, which are much higher. Until recently the corporate income tax rate was 35 percent. Lemma 2 states that the taxation of all startups at a uniform rate would have no impact on an economy's balanced growth path. Differential taxation across VC-funded and non-VC funded startups

and $b_{i j}$ are the $(i, j)$ elements of $A$ and $B$, respectively. Using this measure, the movement from the baseline to random matching represents a distance of 31.9 , whereas the movement from the baseline to perfectly assortative matching amounts to a much larger distance of 95.4. 


\section{Uniform TAXation EXPERIMENT}

\begin{tabular}{lll}
\hline \hline Variable & Baseline & Uniform Taxation \\
Growth & & \\
C.V. & 1.80 & 1.48 \\
$\quad$ VC firms, high & 0 & -5.87 \\
$\quad$ fraction, $\nu_{h}^{v}$ & 0.73 & 0.53 \\
$\quad$ patenting, $x_{h h}^{v}$ and $x_{l h}^{v}$ & $12.99,12.99$ & $10.44,10.14$ \\
$\quad$ success, $\sigma_{h h}^{v}$ and $\sigma_{l h}^{v}$ & $33.11,23.77$ & $24.79,16.52$ \\
$\quad$ VC share of all patenting & 1.28 & 0.74 \\
$\quad$ Non-VC firms, high & & \\
$\quad$ fraction, $\nu_{h}^{n}$ & 99.28 & 99.47 \\
$\quad$ patenting, $x_{h h}^{v}$ and $x_{l h}^{v}$ & $2.63,2.63$ & $2.60,2.59$ \\
$\quad$ success, $\sigma_{h h}^{n}$ and $\sigma_{l h}^{n}$ & $19.53,1.68$ & $19.18,1.64$ \\
Non-VC share of all patenting & 98.72 & 99.26 \\
\hline
\end{tabular}

Table 13: The experiment reports what happens when the tax rate on VC-funded startups is raised from 17 percent to the 35 percent rate on non-VC-funded startups. All rates are reported as percentages.

will though. As an experiment, consider what would have happened if the VC- and nonVC-funded startups were taxed at a uniform rate of 35 percent. Note that the historical tax rates on $\mathrm{VC}$ - and non-VC-funded startups are built into the calibrated synergies, or the $z$ 's. So, the experiment amounts to degrading the synergy factor on VC-funded startups by a factor of $(1.0-0.35) /(1.0-0.17) .{ }^{42}$

When VC-funded startups are taxed at a higher rate, economic growth drops from 1.80 to 1.48 percent per year, as Table 13 shows. Not surprisingly, the level of patenting activity by VC-funded firms in the ex post high state drops. This is not made up for by an increase in patenting activity by non-VC-funded firms. Additionally, VC-funded firms' success rates for making it into the high state drops off sharply. The success rates for non-VC-funded firms does not rise to offset this. The share of VC-funded firms in patenting activity drops fairly dramatically. Since VC-funded are the prime movers in the economy, all of this results in a decline in the growth rate. Raising taxes on VC-funded startups results in a large welfare loss of 5.87 percent in terms of consumption. In other words, the lower tax rates currently applicable to VC-backed startups contribute significantly to growth.

\footnotetext{
${ }^{42}$ This can be gleaned by examining the proof for Lemma 2 in Appendix 12.
} 


\section{Conclusion}

An endogenous growth model is developed to study the implications of venture capital backing on aggregate productivity and innovation. In the model, entrepreneurs take ideas for projects to either banks or venture capitalists for financing. In the U.S. data, startups backed by venture capitalists have more promising growth and innovation prospects than other startups. The initial selection process observed in the data is imposed on the model. Additionally, in the U.S. data, startups that are financed by venture capitalists, as opposed to banks, have a much higher likelihood of making it into the top decile of firms in terms of employment ten years later. They also have much higher rates of growth and patent quality, conditional on surviving. The model's saturated structure allows the framework to be calibrated so that it matches exactly the observed transitions from ex ante promise to ex post success for both bank- and VC-financed firms. It also matches the small ratio of VC-financed to bank-financed startups, the small average firm size in the U.S. economy, and GDP growth per capita.

Simulations of the model establish that the presence of venture capital is key for growth. Shutting down venture capital in the economy reduces growth. In addition, the degree of ex ante assortative matching between startups and financiers matters. Improving the degree of assortative matching from its existing level in the U.S. economy enhances growth, while moving to random matching impedes it. Last, the differential taxation of VC-financed startups is important for growth. If the prevailing tax rates, which imply lower taxation of VC-funded startups compared to others, were to be made uniform across all startups, growth rate of the economy would have declined significantly.

\section{References}

Aghion, Philippe and Peter Howitt. 1992. "A Model of Growth through Creative Destruction." Econometrica 60(2): 323-351.

Antunes, António, Tiago Cavalcanti, and Anne Villamil. 2008. "The Effect of Finan- 
cial Repression and Enforcement on Entrepreneurship and Economic Development." Journal of Monetary Economics 55(2): 278-297.

Ates, Sina. 2014. "Beyond Cash: Venture Capital, Firm Dynamics, and Growth." Unpublished paper, Board of Governors.

Autor, David, David Dorn, Lawrence F. Katz, Christina Patterson, and John Van Reenen. 2017a. "The Fall of the Labor Share and the Rise of Superstar Firms." National Bureau of Economic Research Working Paper 23396.

Bayard, Kimberly, Emin Dinlersoz, Timothy Dunne, John Haltiwanger, Javier Miranda, and John Stevens. 2018. "Early-Stage Business Formation: An Analysis of Applications for Employer Identification Numbers." National Bureau of Economic Research Working Paper 24364.

Bento, Pedro, and Diego Restuccia. 2019. "The Role of Nonemployers in Business Dynamism and Aggregate Productivity." National Bureau of Economic Research Working Paper 25998.

Bernstein, Shai, Xavier Giroud, and Richard Townsend. 2014. "The Impact of Venture Capital Monitoring." Journal of Finance 71(4): 1591-1622.

Bloom, Nicholas, Charles I. Jones, John Van Reenen, and Michael Webb. 2018. "Are Ideas Getting Harder to Find?" National Bureau of Economic Research Working Paper 23783.

Brown, David, John Earle, Mee Jung Kim, and Kyung Min Lee. 2018. "High-Growth Entrepreneurship." IZA Discussion Paper 11662.

Buera, Francisco J., Joseph Kaboski, and Yong Shin, 2011. "Finance and Development: A Tale of Two Sectors." American Economic Review 101(5): 1964-2002.

Castro, Rui, Gian Luca Clementi, and Glenn MacDonald. 2004. "Investor Protection, Optimal Incentives, and Economic Growth." The Quarterly Journal of Economics 119(3): 1131-1175.

Choi, Joonkyu. 2017. "Entrepreneurial Risk Taking, Young Firm Dynamics and Aggregate Implications." Unpublished paper, University of Maryland.

Cole, Harold L., Jeremy Greenwood, and Juan M. Sanchez. 2016. "Why Doesn't Technology Flow from Rich to Poor Countries?" Econometrica 84(4): 1477-1521.

Decker, Ryan, John Haltiwanger, Ron Jarmin, and Javier Miranda. 2016. "Where Has All the Skewness Gone? The Decline in High-Growth (Young) Firms in the U.S." European Economic Review 86(Jul): 4-23.

Erosa, Andres. 2001. "Financial Intermediation and Occupational Choice in Development." Review of Economic Dynamics 4(2): 303-334. 
Gabaix, Xavier. 2011. "The Granular Origins of Aggregate Fluctuations." Econometrica $79(3):$ 733-772.

Gopinath, Gita, Sebnem Kalemli-Ozcan, Loukas Karabarbounis, and Carolina Villegas-Sanchez. 2017. "Capital Allocation and Productivity in South Europe." Quarterly Journal of Economics 132(4): 1915-1967.

Gordon, Robert J. (2016). The Rise and Fall of American Growth: The U.S. Standard of Living since the Civil War. Princeton, N.J.: Princeton University Press.

Graham, Stuart, Cheryl Grim, Tariq Islam, Alan Marco, and Javier Miranda. 2015. "Business Dynamics of Innovating Firms: Linking U.S. Patent Data with Administrative Data on Workers and Firms." Center for Economic Studies Working paper CES-WP-15-19.

Greenwood, Jeremy, Pengfei Han, and Juan M. Sanchez. 2018. "Financing Ventures." National Bureau of Economic Research Working Paper 24808.

Henrekson, Magnus and Tino Sanandaji. 2018. "Stock Option Taxation and Venture Capital Activity: A Cross-Country Study." Venture Capital: An International Journal of Entrepreneurial Finance 20(1): 51-71.

Howell, Sabrina. 2017. "Financing Innovation: Evidence from R\&D Grants." American Economic Review 107(4): 1136-64.

Jovanovic, Boyan and Balazs Szentes. 2013. "On the Market for Venture Capital." Journal of Political Economy 121(3): 493-527.

Klette, Jakob and Samuel Kortum. 2004. "Innovating Firms and Aggregate Innovation." Journal of Political Economy 112(5): 986-1018.

Kortum, Samuel and Josh Lerner. 2000. "Assessing the Contribution of Venture Capital to Innovation." Rand Journal of Economics 31(4): 674-692.

Lentz, Rasmus and Dale T. Mortensen. 2008. "An Empirical Model of Growth Through Product Innovation." Econometrica 76(6): 1317-1373.

Levine, Ross. 2005. "Finance and Growth: Theory and Evidence." Handbook of Economic Growth 1: 865-934.

Midrigan, Virgiliu and Daniel Yi Xu. 2014. "Finance and Misallocation: Evidence from Plant-level Data." American Economic Review 104(2): 422-58.

Moll, Benjamin. 2014. "Productivity Losses from Financial Frictions: Can Selffinancing undo Capital Misallocation?" American Economic Review 104(10): 31863221.

Opp, Christian. 2019. "Venture Capital and the Macroeconomy." Review of Financial Studies, forthcoming. 
Pugsley, Benjamin, Petr Sedlacek, and Vincent Sterk. 2017. "The Nature of Firm Growth." Centre for Macroeconomics Discussion Paper 2017-37.

Puri, Manju and Rebecca Zarutskie. 2012. "On the Life Cycle Dynamics of VentureCapital and Non-Venture-Capital-Financed Firms." Journal of Finance 67(6): 22472293.

Romer, Paul M. 1990. "Endogenous Technological Change." Journal of Political Economy 98(5, pt. 2): S71-S102.

Silveira, Rafael and Randall D. Wright. 2016. "Venture Capital: A Model of Search and Bargaining." Review of Economic Dynamics 19(Jan): 232-246.

Wong, Yuet-Yee. 2019. "Venture Capital Exit and Unobserved Risks." Unpublished paper, Binghamton University.

\section{Appendix: Data}

This Data Appendix describes the assembling of the main dataset and the analysis sample. It also provides further detail about how the tables and figures are constructed.

\subsection{Data merging procedure}

To construct the analysis data, the Thomson-Reuter's VentureXpert data on firms receiving VC funding is combined with the U.S. Census Bureau's Business Register (BR) using probabilistic name and address matching. The resulting data is then linked with the U.S. Census Bureau's Longitudinal Business Database (LBD).

The procedure to combine VentureXpert and BR involves several steps. The first step is to clean the two datasets to facilitate matching. For VC-backed firms between 1970 and 2015, VentureXpert provides the following information: firm identifier, firm name, street address, city, state, zipcode, and the year in which VC funding is received. The analysis uses only firms located in the United States and identifies the first and last years of funding for all such firms. The BR is the main sampling frame for U.S. Census Bureau's surveys and it is the main source data for the LBD. Establishment and firm identifiers, years of operation, and employment from the LBD are integrated with the information on firm name, street address, city, state, and zip code from the BR for the period 1976 through 2013. The firm 
name, street address, city, and zip code variables in both the BR and VentureXpert are standardized using the same protocol.

The second step involves merging VentureXpert with the BR-LBD in a sequential manner using nine passes. Each pass uses a less stringent screening than the previous one, to prevent some valid potential matches from being eliminated. The quality of the matches obtained at the end of the procedure are then assessed, as is discussed below. In each pass, firms are linked based on certain firm name and address criteria, and removed from the set of linked firms before proceeding to the next pass. In the first pass, the merge is based on firm name, street address, city, and state. In the second pass, the merge is performed using firm name, city, state, and zip code. In the third through fifth passes, the merge is done on firm name and two additional address criteria. In the sixth through eight passes, the merge utilizes firm name and one additional address criterion. Finally, in the ninth pass, only firm name is used for matching.

The implementation of the procedure described above results in multiple BR-LBD links for each VC-funded firm. In the third step, the best BR-LBD match is identified for each VC-funded firm using a composite match quality score, which is constructed based on the quality of the name, city, state, and zip code match. To determine the quality of a match, the Jaro-Winkler string comparator is utilized. For each VC-funded firm, only the highest quality BR-LBD links are kept based on the composite score. In the process, low-quality links are also dropped - these are the links based only on name with a low Jaro-Winkler score, and only based on name and one address variable with a low Jaro-Winkler score.

After implementing the above three steps, there still remain multiple BR-LBD links for each VC-funded firm. The fourth step involves validating these links using information on the years in which firms were funded. A link is considered valid if a firm is determined to be active within a five year window of the first and last year of VC funding. In particular, it is required that the funded firm appears in the LBD at least within the first five years of receiving its first VC funding, and that the funded firm not disappear (exit) from the LBD more than five years before receiving its last VC funding. Applying this window also helps account for some potential lags in reporting or recording errors. In cases where multiple links remain, firms whose first year of operation is closest to the founded year recorded by 
VentureXpert are kept. Remaining cases with multiple links are dropped to reduce false positives. Overall, the entire procedure results in a BR-LBD match rate of 70 percent for the VC-funded firms in VentureXpert.

It is important to note that each VC-funded firm is effectively matched to an establishment in the LBD, since the majority of firms in the United States are single-unit (singleestablishment) firms, particularly when they are in the age range when most firms receive VC funding (i.e., when they are very young). The identifier for an establishment is time invariant in the LBD across all the firms an establishment is associated with throughout its life. Hence, an establishment's expansion can be tracked, including the opening of additional establishments under the same firm and M\&A (the funded establishment being subsumed into an existing firm). ${ }^{43}$

\subsection{Analysis sample construction}

The empirical analysis focuses on VC-funded firms that receive funding between 1980 and 2012. This is the period with the best overlapping coverage across all three data sets - LBD, patenting data, and VentureXpert. The last year of the analysis is set to 2012 to take into account lags in the patenting data.

The empirical analysis compares the performance of VC-funded firms with all non-VCfunded firms in the economy. For this purpose, a sample of non-VC-funded firms is assembled using a procedure similar to the construction of the VC-funded firms sample. In particular, between 1980 and 2012 the analysis considers all non-VC-funded firms that are born as single-units and follows the associated establishment identifier across all the firms it is part of throughout its life. Firms that are born as multi-units (a very small fraction of new-born firms) are excluded, as well as those single-unit firms that have an initial age different than zero - these firms are parts of existing businesses.

For both the VC-funded and non-VC-funded firms in the sample, there is information on firm-level industry, age, location (state), multi-unit status, employment, and payroll. Years

\footnotetext{
${ }^{43}$ In cases when the establishment identifier disappears, but the firm identifier associated with the establishment in the last year of the establishment's existence continues, the latest firm the establishment belongs to is followed.
} 
associated with significant events in the firm's life are also identified. These events are firm failure, merger/acquisition, and IPO. Firm failure is identified when all of the establishments of a firm cease to report employment and stop appearing in the LBD. Mergers and acquisitions are identified when one or more of the establishments belonging to a particular firm appear in subsequent years to be part of a different firm that: (i) existed in the two years prior to the acquisition, (ii) continues to exist for at least two years after the acquisition, and (iii) is a multi-unit firm, which means that it operates more than one establishment. IPOs are identified by the first year in which a firm meets two criteria: it appears in the Compustat-BR bridge constructed at the U.S. Census Bureau and records a positive stock price in Compustat.

For each VC-funded firm, the first year in which it received funding is also identified. In addition, firm-level patenting information is brought in using the LBD-PatentsView link file provided by Nikolas Zolas (U.S. Census Bureau). The links identify which firms in the sample engage in patenting activity and allow tracking of a number of innovation outcomes: the number of new patents, the stock of patents, the number of citations received by new patents, and the stock of citations based on patent application year. Two adjustments are made to the citation data. Self-citations are dropped and all citations are scaled by the average citations received by other patents applied for in the same year and same broad NBER technology class.

In the data when VC-backed firms are acquired by existing firms, the firm identifier they are associated with changes. This change often leads to jumps in employment and patenting arising from the fact that the acquiring firm usually operates at a larger scale than the acquired firm. These abrupt changes in firm outcome measures can confound the analysis. Therefore, in cases where mergers or acquisitions are identified, the employment and patenting of the acquired firm are no longer tracked, and the last observed values are used. 


\subsection{Construction of figures and tables}

\subsubsection{Tables 1 and 7}

In Tables 1 and 7, the outcomes of VC-funded and non-VC-funded firms are compared at the time of $\mathrm{VC}$ funding, as well as 10 years after VC funding. First, using the sample of VC-funded firms, average firm age at the first funding event is calculated. This average age (rounded to the nearest integer) is used as the synthetic date to impute a first funding year for all non-VC-funded firms. Second, the analysis is restricted to firms for which the first actual or synthetic funding occurs in 2002 or earlier to ensure that survivors (firms that do not fail or get involved in an M\&A) are observed for a minimum of 10 years. For Table 1, employment at the time of first VC funding is used to separate firms into those in the top 10 percent versus the bottom 90 percent of firm employment at the time of first VC funding. These two groups are further divided into those firms that are funded by venture capitalists versus not. For each group, their shares in the number of firms and employment are calculated for the time of first VC funding. Their shares in VC-funded versus non-VCfunded firms are also computed, as well as their average employment relative to VC-funded firms in the top 10 percent.

In Table 7, the focus is on the subsample of firms that survive 10 years either after first actual or synthetic VC funding. If a firm is involved in an M\&A activity before the 10 year mark, it is also included in the subsample, with the M\&A year being the last observation year for the firm. Firms are separated into two groups based on the distribution of employment 10 years after VC funding - those that fall into the top 10 percent of the distribution versus the bottom 90 percent. The two groups are then further divided into those that were funded by venture capitalists versus those that were not. As in Table 1, for each group statistics on their share of the number of firms and employment 10 years after first VC funding are calculated, as well as average employment and the patent stock relative to VC-funded firms in the top 10 percent.

Transition probabilities between groups in Table 1 and Table 7 are also computed. These are the conditional probabilities with which a firm ends up in each of the four groups 10 years post first funding (Table 7), contingent upon which of the four groups it started in at 
the time of first funding (Table 1) - provided that such a transition is feasible.

\subsubsection{Figure 1}

To generate Figure 1, firm age at first VC funding is calculated as the difference between the first year in which the firm is observed as an employer business in the LBD and the first year of $\mathrm{VC}$ funding. The figure is restricted to those firms that receive funding between the ages of -5 and +5 , where negative numbers indicate that funding was received prior to the first year when the firm hired employees. Firms outside of this age range are not included to prevent the disclosure of confidential information - they account for a small fraction of all firms that receive $\mathrm{VC}$ funding.

\subsubsection{Figures 2 and 3}

To generate Figure 2, the Davis-Haltiwanger-Schuh (DHS) average annual employment growth rate in the firm's first three years of life is calculated. Firm births are associated with an annual growth rate of +2 in the first year of their lives. Firm failures are associated with a DHS growth rate of -2 in the year of failure. The firms in the analysis sample are then grouped into quintiles based on the distribution of DHS average employment growth rate, with the top quintile representing the highest average growth rates. For each quintile, the number of firms that subsequently receive $\mathrm{VC}$ funding is then divided by the total number of firms in that quintile to obtain the percentage probability plotted in the $y$-axis.

To generate Figure 3, the sample is restricted only to patenting firms, and the total quality-adjusted patenting of each firm is calculated over a period of three years starting with the first year of patenting. ${ }^{44}$ This calculation is done before VC funding. Most firms only patent in the first year of the three year period, so effectively this procedure mainly captures the first patenting activity. Firms are then grouped into quintiles based on the quality-adjusted patenting measure, with the highest quintile corresponding to the largest amount of patenting. The y-axis is the ratio of the number of firms that subsequently receive VC funding to the total number of firms in that quintile (expressed as a percentage). The

\footnotetext{
${ }^{44}$ For example, if the first patent of a startup is in 1995, the first three years are 1995, 1996, and 1997.
} 
VC funding probability is based on VC funding observation within the 5 years following the first patent by a firm.

\subsubsection{Figures 4, 5, and 6}

In Figures 4, 5, and 6, the outcomes of funded firms are compared with those of the nonVC-funded firms. The employment, age, industry, and location distributions of VC-funded and non-VC-funded firms are quite different, which may lead to an overstatement of the differences between the two groups. To address these differences that indicate selection, for each VC-funded firm in the sample, matching non-VC-funded firms are found that are observationally similar to the VC-funded firm in the year first VC funding is received. Specifically, for each year in the time frame from 1980 to 2012 a firm that received first VC funding in a year is matched with a non-VC-funded firm in the same year that is of the same age, is in the same narrowly defined employment bin, has the same multi-unit status, is located in the same state, and operates in the same 4-digit NAICS industry.

Ultimately, the matching procedure assigns multiple matches to each VC-funded firm, each of which are given an equal weight in the analysis. Of the nearly 19,000 VC-funded firms in the full sample, approximately 13,000 are matched with non-VC-funded firms that form the control group. ${ }^{45}$ The control group consists of a total of about 649,000 firms. For each VC-funded firm, this procedure sometimes generates multiple matches from the non-VC-funded firm sample, owing to the large set of potential matches available. For the cases with multiple matches, only those matches are kept where the percentage differences in initial employment (at age zero) between the VC-funded and non-VC-funded firms do not exceed 50 percent. After this elimination of multiple matches, there are still cases where multiple non-VC-funded firms match to a single VC-funded firm. In these cases, equal weights are assigned to each matching firm. In certain cases, one non-VC-funded firm also matches to multiple VC-funded firms. To ensure that a single trajectory is followed for the non-VC-funded firm, its earliest match is kept.

For the analysis of firm innovation, a separate set of matched VC-funded and non-VCfunded samples are created following the same procedure described above, but with the

\footnotetext{
${ }^{45}$ All firm counts in the Appendix are rounded to avoid disclosure of confidential information.
} 
additional restriction that treated and control firms have to be patenting firms - a restriction fulfilled by a relatively small number of firms. ${ }^{46}$ The subsample of VC-funded firms that have patents consists of nearly 6,500 firms. Of these about 2,500 are successfully matched based on the criteria described above to about 5,000 non-VC-funded firms that also have patents.

In Figure 4 the evolution of average employment for VC-funded and non-VC-funded firms is plotted. To construct the figure, the sample is restricted to those VC-funded firms (and their non-VC-funded matches) that received funding at ages 1, 2, or 3 and have non-zero employment. These restrictions ensure that the focus is on a sample where firm employment is observed in at least one year prior to the first year of funding. In Figure 6 the sample is also restricted to those VC-funded firms (and their non-VC-funded counterparts) that receive their first funding at age 1,2 , or 3 , but no additional restrictions are placed based on employment.

Using the matched sample, in Figure 5 the focus is on those firms that survive for at least 10 years post VC funding. For each firm, the DHS employment growth rate is calculated between the year in which funding is received and 10 years later. For both the VC-funded and non-VC-funded groups, the kernel density estimate of the resulting growth rate is plotted. The extreme tails of the distributions were trimmed to comply with the disclosure requirements and protect confidentiality.

\subsubsection{Figures 7 and 8, and Table 2}

In Figures 7 and 8, and in Table 2, the focus is on high- versus low-quality venture capitalists. There are several steps involved in assigning VC-funded firms a VC funder quality measure. The VentureXpert data predominately consists of one observation per VC-funded firm per year. Each row of data has a list of funders and the average equity invested per funder. First, a separate indicator is created for each funder, which is used to generate a full list of VC funders in the data. Since the underlying VentureXpert data are obtained from regulatory disclosures, slight variations are observed in the spelling of funder names across deals and over time. In order to take these variations into account, alternate spellings of funder names

\footnotetext{
${ }^{46}$ No matching is done based on patent quality similarity, because many treated firms do not have matched controls that are also close in terms of patent quality similarity.
} 
in the data are taken into account to group these slight variations in spelling under the same identifier. These identifiers are then used to create a measure of total number of deals in which the funder was involved in over the years. A funder is defined to be of high quality (or high experience) if it is in the top 10 percent of the total number of deals distribution, and of low quality (low experience) if it is in the bottom 90 percent.

It is common for a VC-funded firm to receive funding from multiple venture capitalists within the first year of funding. If 50 percent or more of the firms' funders (in counts) are high quality, it is considered to be a firm funded by high-quality venture capitalists. If, instead, more than 50 percent of its funders are low quality, it is considered to be a firm funded by low-quality venture capitalists. As a result, each VC-funded firm is unambiguously classified to be financed by either a high-quality or a low-quality funder for the first year it received VC funding.

In Figures 7 and 8 the sample is restricted to those VC-funded firms that receive their first funding at age 1,2, or 3. The evolution of employment (Figure 7) and patenting (Figure 8) are separately plotted for those firms identified as being funded by high- versus low-quality venture capitalists. In Table 2, the outcomes of firms funded by high- and low-quality funders are compared more formally by using regression analysis. A VC-funded firm's employment in the year of failure, M\&A, or at 10 years out after first VC funding (whichever comes first) is used as the dependent variable. The independent variables are an indicator of whether funding was provided by a high- or low-quality funder (omitted category is the low quality), age at which first funding is received, years since the first funding event, initial firm size (employment) at funding, the amount of equity received at time of first funding, and 4-digit NAICS industry-year fixed effects. 


\section{Appendix: Theory}

Proof. (The Impact of Synergy) The six first-order conditions connected with the Nash Bargaining problem (P1) are

$$
\begin{gathered}
{\left[\delta x_{i j}^{v} z_{i j} I\left(\cdot^{\prime}\right)-\delta p_{i j}^{v}\right] \times\left\{\sigma_{i h}^{v} \delta p_{i h}+\sigma_{i l}^{v} \delta p_{i l}^{v}-R\left(\frac{x_{i h}^{v}}{\mathbf{x}}\right)-R\left(\frac{x_{i l}^{v}}{\mathbf{x}}\right)-D\left(\sigma_{i h}^{v}\right)-D\left(\sigma_{i l}^{v}\right)-V\right\}} \\
+\left\{\sigma_{i h}^{v} \delta x_{i h}^{v} z_{i h}^{v} I\left(\cdot^{\prime}\right)+\sigma_{i l}^{v} \delta x_{i l}^{v} z_{i l}^{v} I\left(\cdot^{\prime}\right)-\sigma_{i h}^{v} \delta p_{i h}^{v}-\sigma_{i l}^{v} \delta p_{i l}^{v}-E_{i}\right\} \times\left[\delta p_{i j}^{v}-D_{1}\left(\sigma_{i j}^{v}\right)\right]=0 \\
\sigma_{i j}^{v} \delta z_{i j}^{v} I\left(\cdot^{\prime}\right) \times\left\{\sigma_{i h}^{v} \delta p_{i h}+\sigma_{i l}^{v} \delta p_{i l}^{v}-R\left(\frac{x_{i h}^{v}}{\mathbf{x}}\right)-R\left(\frac{x_{i l}^{v}}{\mathbf{x}}\right)-D\left(\sigma_{i h}^{v}\right)-D\left(\sigma_{i l}^{v}\right)-V\right\} \\
-\left\{\sigma_{i h}^{v} \delta x_{i h}^{v} z_{i h}^{v} I\left(\cdot^{\prime}\right)+\sigma_{i l}^{v} \delta x_{i l}^{v} z_{i l}^{v} I\left(\cdot^{\prime}\right)-\sigma_{i h}^{v} \delta p_{i h}^{v}-\sigma_{i l}^{v} \delta p_{i l}^{v}-E_{i}\right\} \times R_{1}\left(\frac{x_{i j}^{v}}{\mathbf{x}}\right),
\end{gathered}
$$

and

$$
\begin{aligned}
-\sigma_{i j}^{v} \delta \times\left[\sigma_{i h}^{v} \delta p_{i h}+\right. & \left.\sigma_{i l}^{v} \delta p_{i l}-R\left(\frac{x_{i h}^{v}}{\mathbf{x}}\right)-R\left(\frac{x_{i l}^{v}}{\mathbf{x}}\right)-D\left(\sigma_{i h}^{v}\right)-D\left(\sigma_{i l}^{v}\right)-V\right] \\
& +\left[\sigma_{i h}^{v} \delta x_{i h}^{v} z_{i h}^{v} I\left(\cdot^{\prime}\right)+\sigma_{i l}^{v} \delta x_{i l}^{v} z_{i l}^{v} I\left(\cdot^{\prime}\right)-\sigma_{i h}^{v} \delta p_{i h}^{v}-\sigma_{i l}^{v} \delta p_{i l}^{v}-E_{i}\right] \times \sigma_{i j}^{v} \delta=0,
\end{aligned}
$$

for $j=1,2$. Using the last first-order condition to cancel out the terms in braces in the first two statements leads to the two efficiency conditions (4) and (5). Displacing (4) and (5) with respect to $z_{i j}^{v}$ yields

$$
\left[\begin{array}{cc}
\delta z_{i j}^{v} I^{\prime} & -D_{11} \\
-R_{11} / \mathbf{x}^{2} & \delta z_{i j}^{v} I^{\prime}
\end{array}\right]\left[\begin{array}{l}
d x_{i j}^{v} \\
d \sigma_{i j}^{v}
\end{array}\right]=-\left[\begin{array}{c}
\delta x_{i j}^{v} I^{\prime} \\
\delta \sigma_{i j}^{v} I^{\prime}
\end{array}\right] d z_{i j}^{v},
$$

so that

$$
\frac{d x_{i j}^{v}}{d z_{i j}^{v}}=\frac{-\left(\delta I^{\prime}\right)^{2} x_{i j}^{v} z_{i j}^{v}-\delta \sigma_{i j}^{v} I^{\prime} D_{11}}{\Delta}>0,
$$

and

$$
\frac{d \sigma_{i j}^{v}}{d z_{i j}^{v}}=\frac{-\left(\delta I^{\prime}\right)^{2} z_{i j}^{v} \sigma_{i j}^{v}-\left(R_{11} / \mathbf{x}^{2}\right) \delta x_{i j}^{v} I^{\prime}}{\Delta}>0
$$

with

$$
\Delta \equiv\left(\delta z_{i j}^{v} I^{\prime}\right)^{2}-D_{11} R_{11} / \mathbf{x}^{2}<0
$$


where the sign of $\Delta$ follows from the second-order condition for a maximum. ${ }^{47}$

Proof. (Neutrality of a Uniform Corporate Income Tax on Long-Run Growth) The proof is simple. The profits for an ex ante type- $(f, i, j)$ enterprise will now be $(1-\tau) x_{i j}^{f} z_{i j}^{f}(1-$ $\kappa-\lambda)\left[\left(\frac{\kappa}{r}\right)^{\kappa}\left(\frac{\lambda}{w}\right)^{\lambda}\right]^{1 / \zeta}$. One could rewrite this as $x_{i j}^{f} \widetilde{z}_{i j}^{f}(1-\kappa-\lambda)\left[\left(\frac{\kappa}{r}\right)^{\kappa}\left(\frac{\lambda}{w}\right)^{\lambda}\right]^{1 / \zeta}$, where $\widetilde{z}_{i j}^{f} \equiv$ $(1-\tau) z_{i j}^{f}$. Hence, the introduction of a corporate income tax amounts to an equiproportional renormalization of all of the synergies. From equation (17), it can seen that wages will fall by a factor of $(1-\tau)^{\zeta /(\zeta+\lambda)}$. This fact, in conjunction with $(3)$, implies that the value of a successful venture will drop by this factor too. Last, as can be seen from the first-order conditions for $\sigma_{i j}^{f}$ and $x_{i j}^{f}$, or (4), (5), (8), and (9), the marginal benefits and costs of research and development fall in lock step by same factor $(1-\tau)^{\zeta /(\zeta+\lambda)}$. Therefore, the solutions for $\sigma_{i j}^{f}$ and $x_{i j}^{f}$ are unchanged.

${ }^{47}$ The maximization problem linked to the above two efficiency conditions is

$$
\max _{\sigma_{i j}^{v}, x_{i j}^{v}}\left\{\sigma_{i j}^{v} \delta x_{i j}^{v} z_{i j}^{v} I\left(.^{\prime}\right)-D\left(\sigma_{i j}^{v}\right)-R\left(x_{i j}^{v} / \mathbf{x}\right)\right\} .
$$

For the second-order condition for a maximum to hold, it must transpire that

$$
\left|\begin{array}{cc}
-D_{11} & \delta z_{i j}^{v} I^{\prime} \\
\delta z_{i j}^{v} I^{\prime} & -R_{11} / \mathbf{x}^{2}
\end{array}\right|>0
$$

or that

$$
D_{11} R_{11} / \mathbf{x}^{2}-\left(\delta z_{i j}^{v} I^{\prime}\right)^{2}>0
$$

